TP Periodica Polytechnica Civil Engineering

\author{
62(1), pp. 232-249, 2018 \\ https://doi.org/10.3311/PPci.10679 \\ Creative Commons Attribution (i)
}

RESEARCH ARTICLE

\section{Simplified Time-Dependent Column Shortening Analysis in Special Reinforced Concrete Moment Frames}

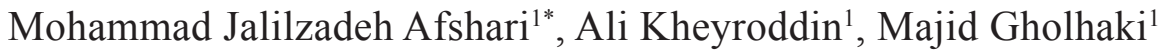

Received 28 February 2017; Revised 30 August 2017; Accepted 06 September 2017

\begin{abstract}
Necessity for adaption of high-rise reinforced concrete structures' design and practical steps of implementation through nonlinear staged analysis by consideration of long-term behavior of concrete have always been strongly recommended by researchers in recent years. Cumulative column shortening in conventional analyses is the most important consequence of neglecting the above issues. In this article, numerous modeling and extensive nonlinear staged analyses are carried out on structures with different geometrical characteristics and extremely simple empirical equations to estimate column shortening caused by creep, shrinkage and time changes of modulus of elasticity are provided in such a way that these relations can be independent of conventional parameters of ACI209R-92 regulations used in prediction of mentioned axial strains. Results obtained from validation of the proposed equations show high compliance of all proposed equations for up to 30 floors and also show accuracy of proposed shrinkage equation for the moment frame structures higher than the studied range.
\end{abstract}

\section{Keywords}

nonlinear sequential construction analysis, conventional one-step analysis, column shortening, creep, shrinkage, time development of modulus of elasticity

\section{Introduction}

\subsection{Research background}

Attention to adaption of structural design with practical implementation steps by applying priority and posteriority of construction schedule into the structural design in form of sequential construction analysis has always been strongly recommended by researchers and scholars in recent years. Basically, all floors of the structure are simultaneously subjected to dead and live loads in conventional structural analyses. While the dead loads of the structural elements and floors are gradually applied to the previously constructed members during the progress of construction which depends on method of construction and its executive arrangements [1] On the other hand, it is obvious that the dead load of newly added elements during construction is carried by the same part of the structure which has been constructed up until that point. Thus, distribution of stresses and displacements caused by the load of existing parts at any stages is independent of size, properties and the presence of other elements which have not entered the construction process [2]. Examples of individuals who studied about above subjects are Choi and Kim (1985) who introduced sequential construction with the concept of active floor in structural analysis [3]. The principles of active floor's analysis are based on three concepts of active floor, inactive floor and deactivated Floors with a reverse order of actual process of construction which is from top to bottom and performing analysis as much as the number of floors in the structure. Use of substructuring technique can be helpful in reduction of number and volume of calculations $[4,5]$. In this method, floor by floor activation process can be done for a group of floors which will increase computing speed and will reduce the time and computational efforts. Choi, Chung, Lee and Wilson presented a simple method to simulate the actual behavior of structure based on practical construction steps in 1992 named Correction Factor Method (CFM) and considered the effects of sequential construction in structural analysis [6]. The mentioned method is able to modify the results of conventional one-step structural analyses only using correction factors and without the need for accurate and time-consuming staged analysis and it is able
${ }^{1}$ Faculty of Civil Engineering, Semnan University, Semnan, Iran.

*Corresponding author's email: jalilzadeh.afshari@semnan.ac.ir 
to make sequential construction effects enter the estimation of internal forces of elements.

On the other hand, numerous results and experiments show that concrete structures basically face a lot of deformations and even excessive stresses due to creep and shrinkage. One of the most important key issues in this case is cumulative column shortening in the conventional one-step analysis which not only leads to imposition of additional moments in horizontal structural elements such as beams due to various axial deformations of adjacent structural elements, but also the error in estimation of gravitational deformation of vertical elements caused by wrong selection of analysis can lead to expansion of progressive cracks in infills or non-structural members elements of some panels with uneven gravitational deformations. Hence, the only way to avoid these adverse effects is estimation of the real behavior of structure which is only possible through nonlinear staged analysis or consideration of all long-term elastic and inelastic strains of concrete. Kim et al. are among researchers who have studied about this issue in 2012 who raised two-step analysis algorithm to accurately estimate columns' shortening [7]. They evaluated the restraining effect of horizontal elements and optimized distribution of additional reinforcement in reducing the extent of shortening respectively in 2013 and 2015 [8, 9]. Sharma et al. evaluated the effect of beam stiffness and Column reinforcement in creep and shrinkage behavior of framed structures in 2009 [10]. Njomo and Ozay in 2014 and Park et al. in 2013 are among researchers who used genetic algorithms to minimize column shortening $[11,12]$. Moragaspitiya et al. provided a numerical model in 2010 to estimate the axial shortenings of concrete structures considering the concrete timedependent phenomena [13]. In 2003, Torres et al. proposed a numerical model for consideration of sequential construction in repairing and strengthening of 2-D reinforced and pre-stressed concrete building frames [14]. Lu et al. also evaluated the longterm behavior of composite structural systems in 2013 [15]. Jalilzadeh Afshari et al. proposed a simplified sequential construction analysis of buildings with a new method of modifying the axial stiffness of columns in 2017 [16].

In addition to mentioned factors, the neglect of structural nonlinear staged analysis of and lack of attention to nature of staged application of gravitational loads can lead to many problems in the analysis and design of high-rise structures (Saffarini and Wilson, 1983 [17], Kwak and Kim, 2006 [2]). Some of these issues are extra induced bending moments in beams caused by unequal axial deformations of adjacent vertical elements which are increasing with time, considerable redistribution of stress between structural elements, increased deflection of concrete beams, expansion of cracks in tensile areas of concrete elements [18] and not using the intended capacity for structural elements in the design stage [19] can be named as undesired effects which are exacerbated by consideration of time-dependent phenomena such as creep and shrinkage which must be considered in form of sequential construction analysis and step by step loading during construction in the design of high-rise reinforced concrete buildings.

The objective of this article is the accurate estimation of column shortening in special moment resisting frame systems using simple empirical equations which are independent of conventional geometrical parameters of common standard methods of estimating the axial time-dependent strains of concrete such as volume to surface ratio or notional size (based on the type of used regulations). Besides the accurate and consistent estimation of shortening due to creep, shrinkage and time changes of characteristic compressive strength and the modulus of elasticity, compared to corresponding values of accurate nonlinear staged analysis, the equations proposed in the present research cover a wide range of special moment resisting frame structures with different heights and geometrical specifications and will be valid only for structures which have been designed optimally based on ACI318-14 regulations [20] and internal forces caused by conventional one-step structural analysis without consideration of long-term effects and time-dependent strains of concrete. In this case, the method proposed in the present study is capable of estimating the longterm behavior of structure in form of creep, shrinkage and elastic shortenings of each column of structure on the $1000^{\text {th }}$ day of construction (as the time indicator when inelastic strains of concrete have almost reached their final value) in accordance with ACI209R-92 regulation [21] and without any need for performing the nonlinear staged analysis and definition of corresponding effective parameters. The aforementioned purpose is achieved just by the use of proposed equations which are only a function of height of column (h), length of span (1), number of floors (n) and the number of intended floor (i).

\subsection{ACI209R-92 regulations}

The method in ACI regulation in form of 209 Committee (ACI209R-92) is the simplest method known among valid method of long term concrete estimation which reflects broader aspects of effective material properties in triple timedependent phenomena of concrete in equations despite the simplicity. In this method, standard conditions are initially defined and predictive equations for time changes of creep and shrinkage are raised based on those. Change and violation of any of the conditions affecting creep or shrinkage of standard regulation appears in equations in form of a correction factor respectively in final values of creep factor or final shrinkage strain. In terms of ACI method, characteristic compressive strength at any time $(\mathrm{t})$ is defined in form of multiplication of time ratio and 28-day characteristic compressive strength of concrete according to Eq. (1). Development of modulus of elasticity with time will also be in form of a function of concrete compressive strength at any desired time and the unit weight of concrete $\left(w_{c}\right)$ in accordance with Eq. (2). 


$$
\begin{gathered}
f_{c}{ }^{\prime}(t)=\frac{t}{\alpha+\beta t} f_{c k} \\
E_{c}(t)=0.043 \times\left(w_{c}\right)^{1.5} \sqrt{f_{c}^{\prime}(t)}
\end{gathered}
$$

In above equations, compressive strengths are in terms of $\mathrm{MPa}$ and unit weight of concrete is in terms of kilograms per cubic meter. $(\alpha)$ and $(\beta)$ are constants depending on curing conditions for concrete and type of cement used with values in Table 1.

Table 1 Constants used in Eq. (1)

\begin{tabular}{lcccc}
\hline constant & \multicolumn{2}{c}{ Moist curing } & \multicolumn{2}{c}{ Steam curing } \\
& $\begin{array}{c}\text { Cement } \\
\text { Type I }\end{array}$ & $\begin{array}{c}\text { Cement } \\
\text { Type III }\end{array}$ & $\begin{array}{c}\text { Cement } \\
\text { Type I }\end{array}$ & $\begin{array}{c}\text { Cement } \\
\text { Type III }\end{array}$ \\
\hline$\alpha$ & 4 & 2.3 & 1 & 0.7 \\
$\beta$ & 0.85 & 0.92 & 0.95 & 0.98 \\
\hline
\end{tabular}

Standard conditions of ACI method to obtain creep and shrinkage equations are as follow;

Loading age equal to 7 days for moist curing and 1 to 3 days for steam curing, 40 percent ambient relative humidity, 38 millimeters volume to surface ratio of element (v/s), 70 millimeters slump, $50 \%$ fine aggregate percentage, air content less than $6 \%$ and the used cements are type I and III with the content between 2.732 to $4.375 \mathrm{kN}$ per cubic meter. All of the above-mentioned conditions are valid at a temperature of 23.2 \pm 2 degrees Celsius. With respect to linear stress and strain relation, Creep strain $\varepsilon_{c r}\left(t, t_{0}\right)$ associated with constant stress $\sigma_{c}\left(t_{0}\right)$ will be according to Eq. (3).

$$
\varepsilon_{c r}\left(t, t_{0}\right)=\sigma_{c}\left(t_{0}\right)\left[\frac{1}{E_{c}\left(t_{0}\right)}+\frac{v\left(t, t_{0}\right)}{E_{c}\left(t_{0}\right)}\right]=\sigma_{c}\left(t_{0}\right) \delta\left(t, t_{0}\right)
$$

Where $E_{c}\left(t_{0}\right)$ is the modulus of elasticity at the time of loading and as a result $1 / E_{c}\left(t_{0}\right)$ indicates initial strain per unit stress at loading and $\delta\left(t, t_{0}\right)$ is the creep compliance and represents the stress-dependent strain per unit stress. Drying creep coefficient is calculated according to Eq. (4).

$$
v_{d}\left(t, t_{0}\right)=\frac{\left(t-t_{0}\right)^{\psi}}{d+\left(t-t_{0}\right)^{\psi}} v_{u}
$$

Where $(t)$ and $\left(t_{0}\right)$ are the age of concrete and age of concrete at loading in terms of days, Respectively. For the mentioned standard conditions, $(\psi)$ is equal to 0.6 and $(d)$ is equal to 10 days and $\left(v_{u}\right)$ is equal to 2.35 . It should be noted that the final creep coefficient $\left(v_{u}\right)$ will be multiplied by correction factor $\left(\gamma_{c}\right)$ which will be equal to 1 in case of meeting all standard condition. Otherwise, it will be in form of the product of coefficients according to Eq. (5).

$$
\gamma_{c}=\gamma_{c}\left(t_{0}\right) \cdot \gamma_{c}(\lambda) \cdot \gamma_{c}(v / s) \cdot \gamma_{c}(s) \cdot \gamma_{c}(\psi) \cdot \gamma_{c}(\alpha)
$$

In which $\gamma_{c}\left(t_{0}\right), \gamma_{c}(\lambda), \gamma_{c}(v / s), \gamma_{c}(s), \gamma_{c}(\psi)$ and $\gamma_{c}(\alpha)$ are respectively the effect of change in standard loading age, standard humidity percentage, standard volume to surface ratio, standard slump, standard fine aggregate percentage and standard air percentage. Equations suggested by ACI209R-92 regulations such as Eq. (6) can be used for estimation of dimensionless coefficient of base creep.

$$
v_{b}\left(t, t_{0}\right)=0.97 \times v_{d}\left(t, t_{0}\right) \times\left(t_{0}\right)^{-(1 / 3)} \times 0.001^{(1 / 8)}
$$

Dimensionless coefficient of ultimate creep $v\left(t, t_{0}\right)$ is obtained by the sum of two basic and drying creep coefficients according to Eq. (7).

$$
v\left(t, t_{0}\right)=v_{d}\left(t, t_{0}\right)+v_{b}\left(t, t_{0}\right)
$$

Shrinkage strain $\left(\varepsilon_{s h}\right)_{t}$ is calculated according to Eq. (8).

$$
\left(\varepsilon_{s h}\right)_{t}=\frac{\left(t-t_{s}\right)^{\eta}}{f+\left(t-t_{s}\right)^{\eta}}\left(\varepsilon_{s h}\right)_{u}
$$

Where $\left(t_{s}\right)$ is the age of concrete when drying starts at the end of moist curing (in days). For mentioned standard conditions, is equal to $1, \mathrm{f}$ is equal to 35 and 55 days respectively for moist curing and steam curing and $\left(\varepsilon_{s h}\right)_{u}$ is equal to 800 $\times 10^{-6}$ and $730 \times 10^{-6}$ respectively for moist curing and steam curing. $780 \times 10^{-6}$ can be used for both curing conditions with proper approximation. The final shrinkage strain will be multiplied by the correction factor which will be equal to 1 in case of meeting all standard conditions. Otherwise, it will be in form of the product of coefficients that each show the effect of change and violation of evaluated parameter from corresponding standard conditions (Eq. 9).

$$
\gamma_{s h}=\gamma_{s h}\left(t_{s}\right) \cdot \gamma_{s h}(\lambda) \cdot \gamma_{s h}(v / s) \cdot \gamma_{s h}(s) \cdot \gamma_{s h}(\psi) \cdot \gamma_{s h}(\alpha) \cdot \gamma_{s h}(c)
$$

Where $\gamma_{s h}\left(t_{s}\right), \gamma_{s h}(\lambda), \gamma_{s h}(v / s), \gamma_{s h}(s), \gamma_{s h}(\psi), \gamma_{s h}(\alpha)$ and $\gamma_{s h}(c)$ are respectively the effect of change in standard concrete age at the beginning of shrinkage, standard humidity percentage, standard volume to surface ratio, standard slump, standard fine aggregate percentage, standard air percentage and standard cement content. $\left(\gamma_{s h}\right)$ should not be lower than 0.2 under any circumstances. Since the ( $\psi$ and $d$ ) in Eq. (4) and ( $\eta$ and $f$ ) in Eq. (8) have been assumed to be constant parameters, the shape and size effect of elements has not been considered in mentioned equations. Equations (10) and (11) can be used instead of previous corresponding values of mentioned parameters for consideration of shape and size effect in creep and shrinkage curves.

$$
\begin{aligned}
& d=26 \exp \left[1.42 \times 10^{-2}(v / s)\right], \psi=1 \\
& f=26 \exp \left[1.42 \times 10^{-2}(v / s)\right], \eta=1
\end{aligned}
$$

\subsection{Modeling validation}

All analyses and designs in the present study for extraction of proposed equations have been carried out in ETABS 2015 software [22]. Therefore, to ensure the accuracy of the software, famous example of Fintel and Khan's Method [23] has been chosen with some minor changes in some assumptions for implementation of ACI209R-92 regulations and compliance with the basic assumptions of this study. Use of Midas Gen 2015 software [24] provides the ability to compare the values 
of creep, shrinkage and elastic shortenings in three modes of ETABS results, manual calculations based on ACI209R-92 regulations and results obtained from Midas Gen 2015 for initial validation and calibration of error. Specifications of evaluated example are as follows:

An internal column of a structure with 36 floors with dimensions of $1.25 \times 0.5$ square meters and floor height of 2.74 meters is considered. axial Dead load of column in all floors is equal to $165 \mathrm{kN}$, Modulus of elasticity of concrete is equal to 25322.51 MPa, characteristic compressive strength of concrete is equal to $25 \mathrm{MPa}$ and the unit weight of concrete is equal to $23.5632 \mathrm{kN} / \mathrm{m}^{3}$. construction Duration of each floor is 7 days, concrete slump is equal to 0.07 meters, used cement is type III with content equal to $4.0726 \mathrm{kN} / \mathrm{m}^{3}$, volume to surface ratio is equal to 0.17857 meter, concrete's fine aggregate percentage is equal to $50 \%$, concrete's air percentage is equal to $6 \%$, ambient relative humidity is equal to $60 \%$, start of shrinkage at the end of moist curing takes 3 days and loading age of floors for ease of calculation is equal to 252 days (equal to the general assumption of conventional one-step analyses in terms of loading time after completion of the last floor).

Since volume to surface ratio $(v / s)$ in millimeters, humidity percentage $(\lambda)$, loading age of floors $\left(t_{0}\right)$ in days, beginning of shrinkage $\left(t_{s}\right)$ in days and cement content $(c)$ in kilograms per cubic meter are the only parameters of conditions in above problem which are different from the standard conditions discussed in ACI209R-92 regulations, the final equations of ACI209R-92 regulations for manual calculations of shortening caused by creep and shrinkage of evaluated column will be obtained in accordance with Eq. (12) and Eq. (13).

$$
\begin{gathered}
\gamma_{c}=\gamma_{c}\left(t_{0}\right) \cdot \gamma_{c}(\lambda) \cdot \gamma_{c}(v / s) \\
\gamma_{s h}=\gamma_{s h}\left(t_{s}\right) \cdot \gamma_{s h}(\lambda) \cdot \gamma_{s h}(v / s) \cdot \gamma_{s h}(c)
\end{gathered}
$$

Where $\gamma_{c}\left(t_{0}\right), \gamma_{c}(\lambda), \gamma_{c}(v / s), \gamma_{s h}\left(t_{s}\right), \gamma_{s h}(\lambda), \gamma_{s h}(v / s)$ and $\gamma_{s h}(c)$ are respectively calculated using Eq. (14) to Eq. (20) with assumption of moist curing:

$$
\begin{gathered}
\gamma_{c}\left(t_{0}\right)=1.25\left(t_{0}\right)^{-0.118} \\
\gamma_{c}(\lambda)=1.27-0.0067 \lambda \lambda>40 \% \\
\gamma_{c}(v / s)=(2 / 3)\{1+1.13 \exp [-0.0213(v / s)]\} \\
\gamma_{s h}\left(t_{s}\right)=1.202-0.2337 \log \left(t_{s}\right) \\
\gamma_{s h}(\lambda)=1.4-0.0102 \lambda \quad 40 \% \leq \lambda \leq 80 \% \\
\gamma_{s h}(v / s)=1.2 \exp [-0.00472(v / s)] \\
\gamma_{s h}(c)=0.75+0.00061 c
\end{gathered}
$$

The final results of manual calculations using ACI209R-92 method and the corresponding software results of ETABS and Midas Gen applications about shortening of the mentioned column due to the effects of creep and shrinkage and modulus of elasticity in $1000^{\text {th }}$ day of construction have been shown in Fig. 1. As it can be observed, the maximum errors in estimation of actual values of column's creep behavior for Midas Gen and ETABS software have been respectively reported to be equal to 3.33 percent and 0.55 percent. Full compliance of elastic shortening curves and extremely appropriate compliance of creep and shrinkage shortening curves in three evaluated modes confirm the accuracy of calculations and performance of software used in the present research (ETABS).

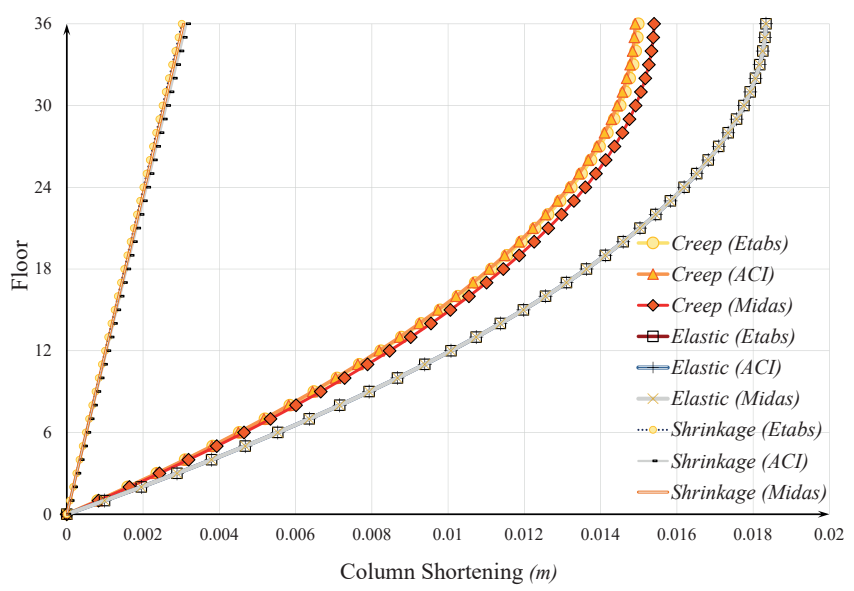

Fig. 1 Comparison of shortening values in three evaluated modes

\section{Modeling}

Different special moment resisting frames with different geometric conditions have been modeled in order to move in direction of objective of the present article and achieve simple equations to estimate the staged long-term behavior of structure. Loading of all evaluated models has been carried out in accordance with ASCE7-10 regulations [25] and their typical designing with identical sections for each particular floor has been done to the most optimal way possible based on ACI318-14 regulations and the results of conventional onestep analysis (regardless of time-dependent parameters of concrete). Simple relations ruling the shortening of columns based on ACI209R-92 regulations are extracted through nonlinear staged analyses after the mentioned conventional design. Hence, it is obvious that final proposed equations of the present study will only be valid for structures which initially have geometric characteristics (plan and height dimensions) within the range of the present research which will be introduced in the following sections and secondly, their design is based on conventional one-step analyses of mentioned regulation in optimum form.

\subsection{Specifications used in structural design}

9 framed structure with 3 types of separate plan with geometric characteristics mentioned in Fig. 2 each of which has three modes of 10, 20 and 30 floors have been considered with nomenclature mentioned in Fig. 2 in order to evaluate the effect of span length and number of floors on column shortening. 

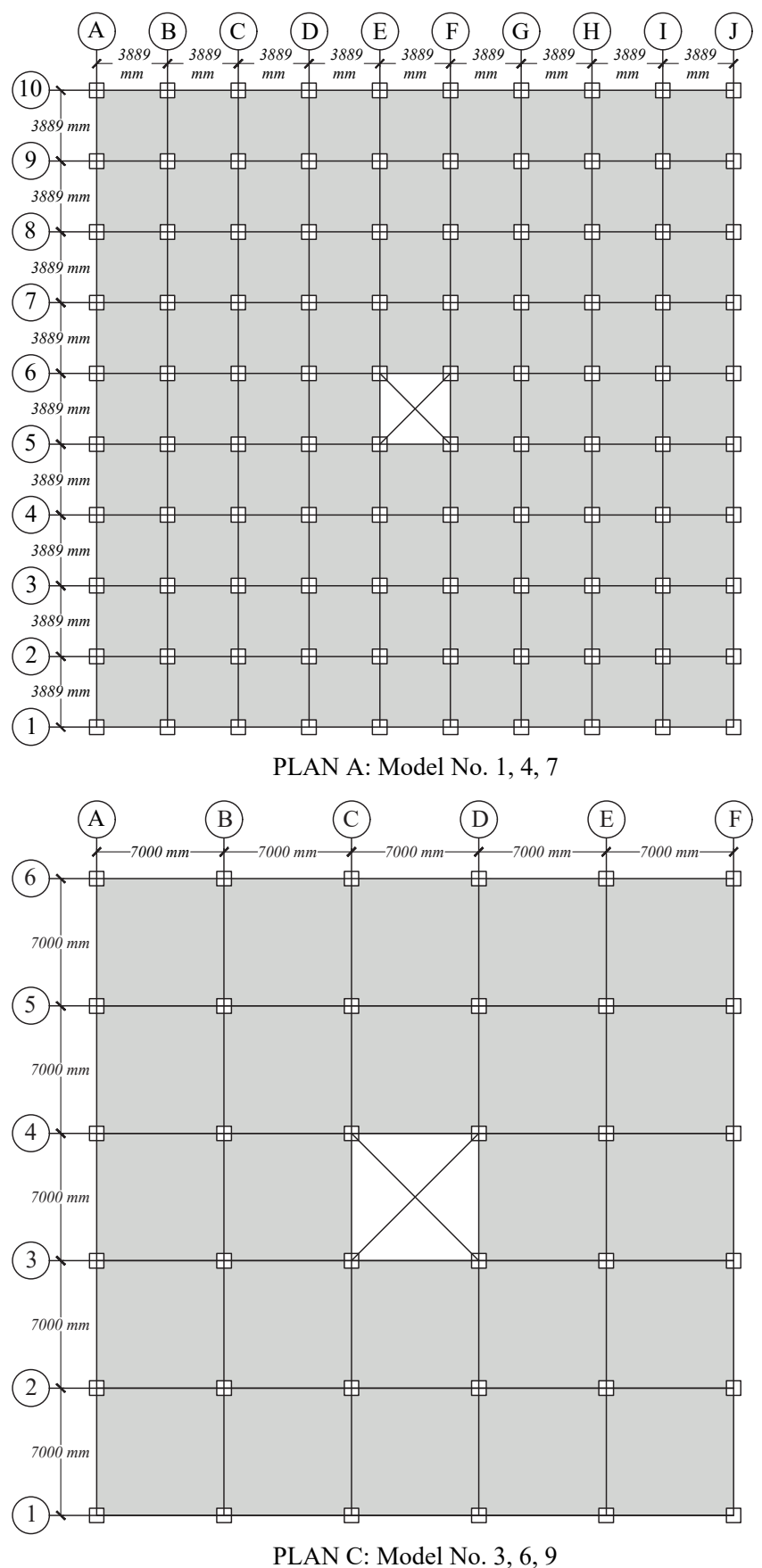

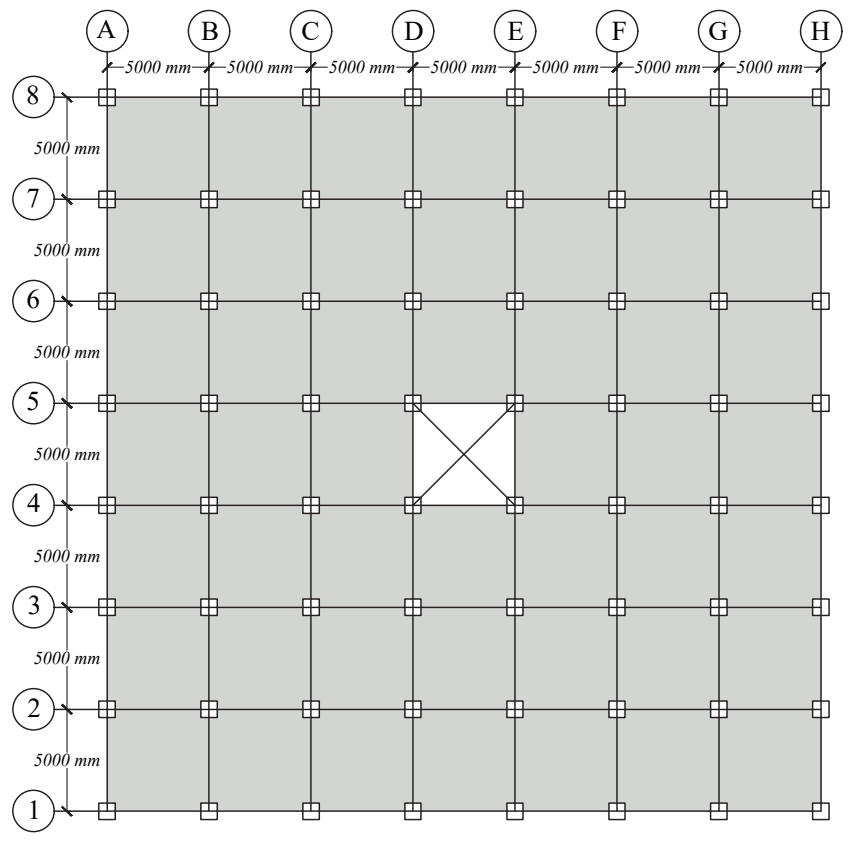

PLAN B: Model No. 2, 5, 8

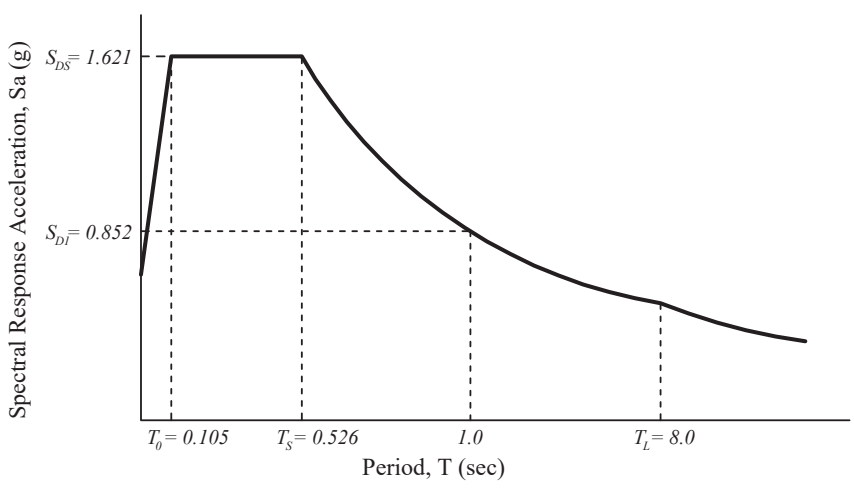

$\begin{array}{lcr}\text { Model's Name } & \text { Plan Type } & \text { Number o } \\ \text { Model No. 1 } & \text { A } & 10 \\ \text { Model No. } 2 & \text { B } & 10 \\ \text { Model No. } 3 & \text { C } & 10 \\ \text { Model No. } 4 & \text { A } & 20 \\ \text { Model No. 5 } & \text { B } & 20 \\ \text { Model No. } 6 & \text { C } & 20 \\ \text { Model No. } 7 & \text { A } & 30 \\ \text { Model No. } 8 & \text { B } & 30 \\ \text { Model No. } 9 & \text { C } & 30\end{array}$

Fig. 2 Design and geometry specifications of plans for evaluated models

Analysis of all structures with 10 floors (models 1 to 3 ) has been carried out using equivalent lateral force analysis and analysis of other structures (models 4 to 9 ) has been carried out using modal response spectrum analysis. The rebar used for Reinforcement is ASTM A706 Gr60 based on ACI318-14 special seismic standards. Characteristic compressive strength of concrete is considered to be equal to $25 \mathrm{MPa}$ and height of floors is considered to be equal to 3.5 meters. Roof system for all structures is two-way concrete slab with the size of 180 $\mathrm{mm}$ which has a dead load equal to $4.241 \mathrm{kN}$ per square meter for all floors with respect to unit weight of concrete equal to $23.5432 \mathrm{kN} / \mathrm{m}^{3}$. Super dead load including finishing load for roof and floors of structure and equivalent load of interior partitions has been assumed to be respectively equal to 1.496
$\mathrm{kN} / \mathrm{m}^{2}, 1.152 \mathrm{KN} / \mathrm{m}^{2}$ and $0.98067 \mathrm{kN} / \mathrm{m}^{2}$. Super dead load of perimeter walls is $6.865 \mathrm{kN} / \mathrm{m}$. The residential structures are located in Los Angeles with spectral response accelerations shown in Fig. 2 and other seismic design parameters shown in Table 2. The diameter of transverse reinforcement of vertical elements is $10 \mathrm{~mm}$ and has been selected with spacing and the number of legs proportional to the dimensions of column for effective confinement in each selected cross section. Cross sections of elements obtained from detailed and optimum design of structures for models 1 to 3 , models 4 to 6 and models 7 to 9 have been listed respectively in Tables 3, 4 and 5 . 


\subsection{Nonlinear staged analysis Specifications}

The most important criteria used in staged analysis of conventionally designed structures is determination of construction process and specified construction time for each floor and loading ages of floors. The loading age $\left.t_{0}\right)$ of all floors (i.e. time needed for installation of formwork and concreting till the removal of formwork which is defined as the beginning of loading) has been considered to be equal to 7-day construction duration of the floors for simplicity. Age of concrete at the beginning of shrinkage $\left(t_{s}\right)$ and ambient relative humidity has been selected to be 3 days and 60 percent, Respectively.
Table 2 Seismic specifications used in the design of structures

\begin{tabular}{cc}
\hline Design specification & value \\
\hline Site Class - Seismic Design Category & $\mathrm{D}-\mathrm{E}$ \\
Redundancy factor, $\rho$ & 1 \\
Response Modification Coefficient, R & 8 \\
Overstrength Factor, $\Omega_{0}$ & 3 \\
Deflection Amplification Factor, Cd & 5.5 \\
Seismic Importance Factor, Ie - Risk Category & $1-\mathrm{II}$ \\
\hline
\end{tabular}

Table 3 Cross sectional specifications of elements in models 1, 2 and 3

\begin{tabular}{|c|c|c|c|c|c|c|}
\hline \multirow[t]{2}{*}{ Story } & \multicolumn{2}{|c|}{ Model No. 1} & \multicolumn{2}{|c|}{ Model No. 2} & \multicolumn{2}{|c|}{ Model No. 3} \\
\hline & Beam dim. $(\mathrm{mm})^{*}$ & Column Dim. (mm) & Beam Dim. (mm)* & Column Dim. (mm) & Beam Dim. (mm)* & Column Dim. (mm) \\
\hline 10 & $300 \times 300$ & $300 \times 30016 \mathrm{~T} 16$ & $300 \times 300$ & $400 \times 40016 \mathrm{~T} 20$ & $450 \times 400$ & $550 \times 55016 \mathrm{~T} 22$ \\
\hline 9 & $350 \times 350$ & $400 \times 40016 \mathrm{~T} 16$ & $400 \times 450$ & $450 \times 45016 \mathrm{~T} 25$ & $450 \times 500$ & $550 \times 55016 \mathrm{~T} 22$ \\
\hline 8 & $400 \times 400$ & $450 \times 45016 \mathrm{~T} 16$ & $450 \times 450$ & $500 \times 50016 \mathrm{~T} 22$ & $500 \times 650$ & $550 \times 55016 \mathrm{~T} 25$ \\
\hline 7 & $400 \times 400$ & $450 \times 45016 \mathrm{~T} 16$ & $500 \times 500$ & $500 \times 50016 \mathrm{~T} 22$ & $650 \times 650$ & $600 \times 60016 \mathrm{~T} 25$ \\
\hline 6 & $450 \times 450$ & $450 \times 45016 \mathrm{~T} 16$ & $500 \times 550$ & $550 \times 55016 \mathrm{~T} 20$ & $650 \times 650$ & $650 \times 65016 \mathrm{~T} 28$ \\
\hline 5 & $450 \times 450$ & $450 \times 45016 \mathrm{~T} 16$ & $500 \times 550$ & $550 \times 55016 \mathrm{~T} 25$ & $650 \times 700$ & $650 \times 65016 \mathrm{~T} 28$ \\
\hline 4 & $450 \times 500$ & $450 \times 45016 \mathrm{~T} 18$ & $550 \times 550$ & $600 \times 60016 \mathrm{~T} 20$ & $700 \times 700$ & $700 \times 70016 \mathrm{~T} 25$ \\
\hline 3 & $450 \times 500$ & $450 \times 45016 \mathrm{~T} 20$ & $550 \times 550$ & $600 \times 60016 \mathrm{~T} 20$ & $700 \times 700$ & $700 \times 70016 \mathrm{~T} 28$ \\
\hline 2 & $450 \times 500$ & $450 \times 45016 \mathrm{~T} 25$ & $550 \times 550$ & $600 \times 60016 \mathrm{~T} 20$ & $700 \times 700$ & $700 \times 70016 \mathrm{~T} 28$ \\
\hline 1 & $450 \times 500$ & $450 \times 45016 \mathrm{~T} 25$ & $550 \times 550$ & $600 \times 60016 \mathrm{~T} 20$ & $700 \times 700$ & $750 \times 75016 \mathrm{~T} 32$ \\
\hline
\end{tabular}

Note*: beam dimensions are presented in form of width $\times$ depth

Table 4 Cross sectional specifications of elements in models 4,5 and 6

\begin{tabular}{|c|c|c|c|c|c|c|}
\hline \multirow[t]{2}{*}{ Story } & \multicolumn{2}{|c|}{ Model No. 4} & \multicolumn{2}{|c|}{ Model No. 5} & \multicolumn{2}{|c|}{ Model No. 6} \\
\hline & Beam dim. $(\mathrm{mm}) *$ & Column Dim. (mm) & Beam Dim. (mm)* & Column Dim. (mm) & Beam Dim. (mm)* & Column Dim. (mm) \\
\hline 20 & $300 \times 350$ & $300 \times 30016 \mathrm{~T} 18$ & $350 \times 350$ & $400 \times 40016 \mathrm{~T} 20$ & $400 \times 450$ & $500 \times 50016 \mathrm{~T} 25$ \\
\hline 19 & $350 \times 350$ & $400 \times 40016 \mathrm{~T} 18$ & $400 \times 400$ & $450 \times 450 \quad 16 \mathrm{~T} 25$ & $450 \times 500$ & $550 \times 550 \quad 16 \mathrm{~T} 25$ \\
\hline 18 & $400 \times 350$ & $500 \times 50016 \mathrm{~T} 16$ & $450 \times 450$ & $500 \times 50016 \mathrm{~T} 20$ & $550 \times 600$ & $600 \times 60016 \mathrm{~T} 20$ \\
\hline 17 & $450 \times 350$ & $500 \times 50016 \mathrm{~T} 16$ & $450 \times 450$ & $550 \times 55016 \mathrm{~T} 20$ & $550 \times 600$ & $600 \times 60016 \mathrm{~T} 25$ \\
\hline 16 & $450 \times 400$ & $500 \times 50016 \mathrm{~T} 16$ & $500 \times 500$ & $550 \times 55016 \mathrm{~T} 20$ & $650 \times 650$ & $650 \times 65016 \mathrm{~T} 28$ \\
\hline 15 & $450 \times 400$ & $500 \times 50016 \mathrm{~T} 20$ & $550 \times 500$ & $600 \times 60016 \mathrm{~T} 20$ & $650 \times 650$ & $700 \times 70016 \mathrm{~T} 25$ \\
\hline 14 & $450 \times 450$ & $500 \times 50016 \mathrm{~T} 22$ & $550 \times 500$ & $600 \times 60016 \mathrm{~T} 20$ & $700 \times 650$ & $700 \times 70016 \mathrm{~T} 25$ \\
\hline 13 & $500 \times 450$ & $550 \times 55016 \mathrm{~T} 20$ & $550 \times 550$ & $600 \times 60016 \mathrm{~T} 20$ & $700 \times 700$ & $700 \times 70016 \mathrm{~T} 28$ \\
\hline 12 & $500 \times 450$ & $550 \times 55016 \mathrm{~T} 20$ & $600 \times 550$ & $650 \times 65016 \mathrm{~T} 25$ & $750 \times 700$ & $700 \times 70020 \mathrm{~T} 32$ \\
\hline 11 & $500 \times 450$ & $550 \times 55016 \mathrm{~T} 20$ & $600 \times 550$ & $650 \times 65016 \mathrm{~T} 25$ & $750 \times 750$ & $750 \times 75016 \mathrm{~T} 28$ \\
\hline 10 & $500 \times 500$ & $550 \times 55016 \mathrm{~T} 20$ & $600 \times 550$ & $650 \times 65016 \mathrm{~T} 25$ & $750 \times 750$ & $750 \times 75024 \mathrm{~T} 32$ \\
\hline 9 & $500 \times 500$ & $550 \times 55016 \mathrm{~T} 20$ & $600 \times 600$ & $650 \times 65016 \mathrm{~T} 25$ & $750 \times 750$ & $800 \times 80020 \mathrm{~T} 32$ \\
\hline 8 & $500 \times 500$ & $550 \times 55016 \mathrm{~T} 20$ & $600 \times 600$ & $650 \times 65016 \mathrm{~T} 25$ & $800 \times 750$ & $800 \times 80024 \mathrm{~T} 32$ \\
\hline 7 & $550 \times 500$ & $600 \times 60016 \mathrm{~T} 20$ & $650 \times 600$ & $650 \times 65016 \mathrm{~T} 28$ & $800 \times 750$ & $850 \times 85024 \mathrm{~T} 32$ \\
\hline 6 & $550 \times 500$ & $600 \times 60016 \mathrm{~T} 20$ & $650 \times 600$ & $700 \times 70016 \mathrm{~T} 25$ & $850 \times 750$ & $850 \times 85028 \mathrm{~T} 32$ \\
\hline 5 & $600 \times 500$ & $600 \times 600 \quad 16 \mathrm{~T} 20$ & $700 \times 600$ & $700 \times 70016 \mathrm{~T} 28$ & $900 \times 750$ & $900 \times 90032 \mathrm{~T} 28$ \\
\hline 4 & $600 \times 500$ & $650 \times 65016 \mathrm{~T} 25$ & $700 \times 600$ & $700 \times 70020 \mathrm{~T} 32$ & $900 \times 750$ & $950 \times 95032 \mathrm{~T} 28$ \\
\hline 3 & $600 \times 500$ & $650 \times 65016 \mathrm{~T} 25$ & $750 \times 600$ & $750 \times 750 \quad 16 \mathrm{~T} 28$ & $900 \times 750$ & $950 \times 95032 \mathrm{~T} 32$ \\
\hline 2 & $600 \times 500$ & $650 \times 65016 \mathrm{~T} 25$ & $750 \times 600$ & $750 \times 75016 \mathrm{~T} 32$ & $950 \times 750$ & $1000 \times 100032 \mathrm{~T} 32$ \\
\hline 1 & $600 \times 500$ & $650 \times 65016 \mathrm{~T} 32$ & $750 \times 600$ & $750 \times 75024 \mathrm{~T} 32$ & $950 \times 750$ & $1050 \times 105032 \mathrm{~T} 32$ \\
\hline
\end{tabular}


Table 5 Cross sectional specifications of elements in models 7, 8 and 9

\begin{tabular}{|c|c|c|c|c|c|c|}
\hline \multirow[t]{2}{*}{ Story } & \multicolumn{2}{|c|}{ Model No. 7} & \multicolumn{2}{|c|}{ Model No. 8} & \multicolumn{2}{|c|}{ Model No. 9} \\
\hline & Beam dim. (mm)* & Column Dim. (mm) & Beam Dim. (mm)* & Column Dim. (mm) & Beam Dim. (mm)* & Column Dim. (mm) \\
\hline 30 & $350 \times 300$ & $350 \times 35016 \mathrm{~T} 16$ & $350 \times 450$ & $400 \times 40016 \mathrm{~T} 22$ & $500 \times 450$ & $500 \times 50016 \mathrm{~T} 28$ \\
\hline 29 & $350 \times 300$ & $450 \times 45016 \mathrm{~T} 16$ & $350 \times 450$ & $450 \times 45016 \mathrm{~T} 25$ & $500 \times 600$ & $550 \times 55016 \mathrm{~T} 25$ \\
\hline 28 & $400 \times 400$ & $500 \times 50016 \mathrm{~T} 20$ & $450 \times 500$ & $550 \times 55016 \mathrm{~T} 20$ & $550 \times 600$ & $650 \times 65016 \mathrm{~T} 25$ \\
\hline 27 & $400 \times 400$ & $500 \times 50016 \mathrm{~T} 28$ & $450 \times 500$ & $550 \times 55016 \mathrm{~T} 22$ & $600 \times 650$ & $700 \times 70016 \mathrm{~T} 25$ \\
\hline 26 & $450 \times 450$ & $550 \times 55016 \mathrm{~T} 20$ & $450 \times 550$ & $600 \times 60016 \mathrm{~T} 22$ & $650 \times 700$ & $700 \times 70016 \mathrm{~T} 28$ \\
\hline 25 & $500 \times 450$ & $550 \times 55016 \mathrm{~T} 20$ & $450 \times 600$ & $600 \times 60016 \mathrm{~T} 22$ & $650 \times 700$ & $700 \times 70020 \mathrm{~T} 32$ \\
\hline 24 & $500 \times 450$ & $600 \times 60016 \mathrm{~T} 20$ & $450 \times 600$ & $600 \times 60016 \mathrm{~T} 25$ & $700 \times 750$ & $750 \times 75016 \mathrm{~T} 28$ \\
\hline 23 & $500 \times 450$ & $600 \times 60016 \mathrm{~T} 20$ & $450 \times 650$ & $600 \times 60016 \mathrm{~T} 28$ & $700 \times 750$ & $750 \times 75024 \mathrm{~T} 32$ \\
\hline 22 & $500 \times 500$ & $600 \times 60016 \mathrm{~T} 20$ & $500 \times 650$ & $650 \times 65016 \mathrm{~T} 25$ & $700 \times 800$ & $800 \times 80020 \mathrm{~T} 28$ \\
\hline 21 & $500 \times 500$ & $600 \times 60016 \mathrm{~T} 20$ & $500 \times 650$ & $650 \times 65016 \mathrm{~T} 25$ & $700 \times 800$ & $800 \times 80020 \mathrm{~T} 32$ \\
\hline 20 & $500 \times 550$ & $600 \times 60016 \mathrm{~T} 25$ & $550 \times 650$ & $650 \times 65016 \mathrm{~T} 25$ & $700 \times 850$ & $800 \times 80024 \mathrm{~T} 32$ \\
\hline 19 & $500 \times 550$ & $600 \times 60016 \mathrm{~T} 25$ & $550 \times 650$ & $700 \times 70016 \mathrm{~T} 25$ & $700 \times 850$ & $800 \times 80028 \mathrm{~T} 32$ \\
\hline 18 & $500 \times 550$ & $600 \times 60016 \mathrm{~T} 25$ & $550 \times 650$ & $700 \times 70016 \mathrm{~T} 25$ & $700 \times 850$ & $850 \times 85028 \mathrm{~T} 32$ \\
\hline 17 & $500 \times 550$ & $650 \times 65016 \mathrm{~T} 25$ & $550 \times 700$ & $700 \times 70016 \mathrm{~T} 28$ & $750 \times 850$ & $900 \times 90032 \mathrm{~T} 28$ \\
\hline 16 & $550 \times 550$ & $650 \times 65016 \mathrm{~T} 25$ & $550 \times 700$ & $700 \times 70020 \mathrm{~T} 32$ & $750 \times 850$ & $900 \times 90032 \mathrm{~T} 32$ \\
\hline 15 & $550 \times 550$ & $650 \times 65016 \mathrm{~T} 25$ & $600 \times 700$ & $700 \times 70020 \mathrm{~T} 32$ & $800 \times 850$ & $950 \times 95032 \mathrm{~T} 32$ \\
\hline 14 & $600 \times 550$ & $650 \times 65016 \mathrm{~T} 25$ & $600 \times 700$ & $750 \times 75016 \mathrm{~T} 32$ & $850 \times 850$ & $950 \times 95032 \mathrm{~T} 32$ \\
\hline 13 & $600 \times 550$ & $700 \times 70016 \mathrm{~T} 25$ & $600 \times 700$ & $750 \times 75024 \mathrm{~T} 32$ & $850 \times 850$ & $1000 \times 100032 \mathrm{~T} 32$ \\
\hline 12 & $600 \times 550$ & $700 \times 70016 \mathrm{~T} 25$ & $600 \times 700$ & $800 \times 80020 \mathrm{~T} 28$ & $900 \times 850$ & $1000 \times 100036 \mathrm{~T} 32$ \\
\hline 11 & $650 \times 550$ & $700 \times 70016 \mathrm{~T} 25$ & $600 \times 700$ & $800 \times 80020 \mathrm{~T} 32$ & $900 \times 850$ & $1050 \times 105036 \mathrm{~T} 32$ \\
\hline 10 & $650 \times 550$ & $700 \times 70016 \mathrm{~T} 25$ & $600 \times 700$ & $800 \times 80024 \mathrm{~T} 32$ & $900 \times 850$ & $1050 \times 105044 \mathrm{~T} 32$ \\
\hline 9 & $650 \times 550$ & $700 \times 70016 \mathrm{~T} 28$ & $650 \times 700$ & $800 \times 80028 \mathrm{~T} 32$ & $900 \times 850$ & $1100 \times 110044 \mathrm{~T} 32$ \\
\hline 8 & $650 \times 550$ & $700 \times 70020 \mathrm{~T} 32$ & $650 \times 700$ & $850 \times 85028 \mathrm{~T} 32$ & $950 \times 850$ & $1150 \times 115044 \mathrm{~T} 32$ \\
\hline 7 & $650 \times 600$ & $700 \times 70020 \mathrm{~T} 32$ & $650 \times 700$ & $900 \times 90032 \mathrm{~T} 28$ & $950 \times 850$ & $1200 \times 120048 \mathrm{~T} 32$ \\
\hline 6 & $650 \times 600$ & $700 \times 70020 \mathrm{~T} 32$ & $700 \times 700$ & $900 \times 90032 \mathrm{~T} 32$ & $950 \times 850$ & $1200 \times 120052 \mathrm{~T} 32$ \\
\hline 5 & $650 \times 600$ & $750 \times 75024 \mathrm{~T} 32$ & $750 \times 700$ & $950 \times 95032 \mathrm{~T} 32$ & $1000 \times 850$ & $1250 \times 125048 \mathrm{~T} 32$ \\
\hline 4 & $650 \times 600$ & $750 \times 75024 \mathrm{~T} 32$ & $750 \times 700$ & $950 \times 95032 \mathrm{~T} 32$ & $1000 \times 850$ & $1250 \times 125056 \mathrm{~T} 32$ \\
\hline 3 & $650 \times 600$ & $750 \times 75024 \mathrm{~T} 32$ & $750 \times 700$ & $1000 \times 100032 \mathrm{~T} 32$ & $1000 \times 850$ & $1300 \times 130056 \mathrm{~T} 32$ \\
\hline 2 & $650 \times 600$ & $800 \times 80024 \mathrm{~T} 32$ & $750 \times 700$ & $1000 \times 100036 \mathrm{~T} 32$ & $1000 \times 850$ & $1300 \times 130064 \mathrm{~T} 32$ \\
\hline 1 & $650 \times 600$ & $800 \times 80028 \mathrm{~T} 32$ & $800 \times 700$ & $1050 \times 105040 \mathrm{~T} 32$ & $1050 \times 850$ & $1350 \times 135068 \mathrm{~T} 32$ \\
\hline
\end{tabular}

Concrete's fine aggregate percentage, air percentage and slump of concrete have been considered based on standard conditions mentioned in ACI209R-92 regulations and strength specifications of used material have been assumed to be equal to basic assumptions made in modeling validation section. It should be noted that volume to surface ratio for each structural element is automatically calculated by software in nonlinear staged analysis phase. As previously discussed, the mentioned quantity has not been reflected in final proposed equations of research. The independence of proposed equations of the present research from volume to surface ratio is considered as the advantage of method used in this research with respect to initial deeds about using optimal sections in design stage. gravity load combination used in sequential construction analysis is in form of Eq. (21).

$$
D_{L}+0.2 L_{L}
$$

In whichis $\left(D_{L}\right)$ the dead load caused by weight of structure which includes beam, column and slabs and $\left(L_{L}\right)$ is the live load considered for residential structures based on ASCE7-10 regulations. Consideration of a percentage of live loads in nonlinear staged calculations of structures is due to the fact that potential effects arising from serviceability performance of some floors such as finishing or partitioning which may occur before the completion of all floors are applied in the analysis. Sensitivity analysis for bending moment of beams to the sequential construction has been carried out after performing nonlinear staged analyses and obtaining the values of shortening due to creep, shrinkage and time changes in modulus of elasticity for all columns of the 9 evaluated models. The mentioned analysis has been carried out in order to determine columns defining the most sensitive beams to long-term nonlinear staged behavior of vertical elements and ultimately classification of columns with similar behavior. 


\subsection{Sensitivity analysis}

Level of sensitivity of negative moment at the beginning of span of all beams to sequential construction has been measured using dimensionless coefficient of SI. The mentioned coefficient is obtained using Eq. (22) by division of negative moment at the beginning of span of beams caused by Nonlinear Staged Analysis without long-term effects of concrete $\left(M_{N S A}^{-}\right)$on corresponding values caused by Conventional onestep Analysis without long-term effects of concrete $\left(M_{C A}^{-}\right)$. The load combination used in calculation of each of two mentioned moments under related analyses is in form of Eq. (21).

$$
S I=M_{N S A}^{-} / M_{C A}^{-}
$$

Closeness of above coefficient to one means insensitivity of evaluated element to sequential construction and larger deviation coefficient from one means greater sensitivity of that element. Sensitivity analysis of all models have led to similar results. The mentioned results have been shown as examples for models 3, 5 and 7 respectively in Fig. 3, Fig. 4 and Fig. 5. Beams of each structure which have had similar sensitivity to sequential construction have been classified with same color in all of the above figures.

As it can be observed, the most sensitive beams in model number 3 are respectively beams labeled as 1, 4 and 6 in Legend of the related figure (red, cyan and purple color codes). The most sensitive beams in model number 5 are respectively beams labeled as 1, 4 and 9 in Legend of the related figure (red, cyan and gray color codes) and the most sensitive beams in model number 7 are respectively beams labeled as 1, 4 and 11 in Legend of the related figure (red, cyan and blue color codes).

Doubled precision in mentioned sensitive beams makes it clear that all mentioned beams are interfaces between columns with different tributary areas. Hence, selection of a criteria for specific classification of columns in plan and allocation of suggested shortening equations to respective classes is obvious and it will be discussed in the following section.

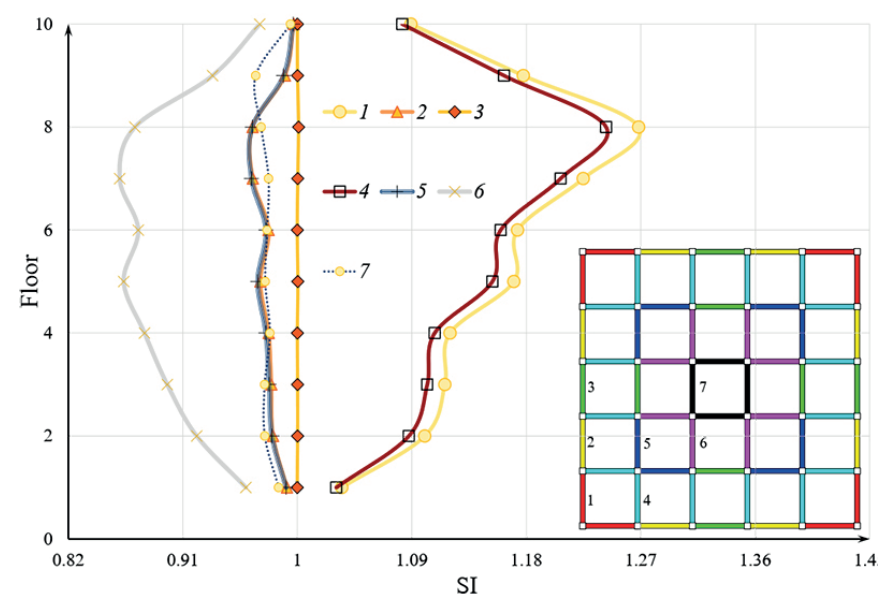

Fig. 3 Sensitivity analysis of beams in model number 3

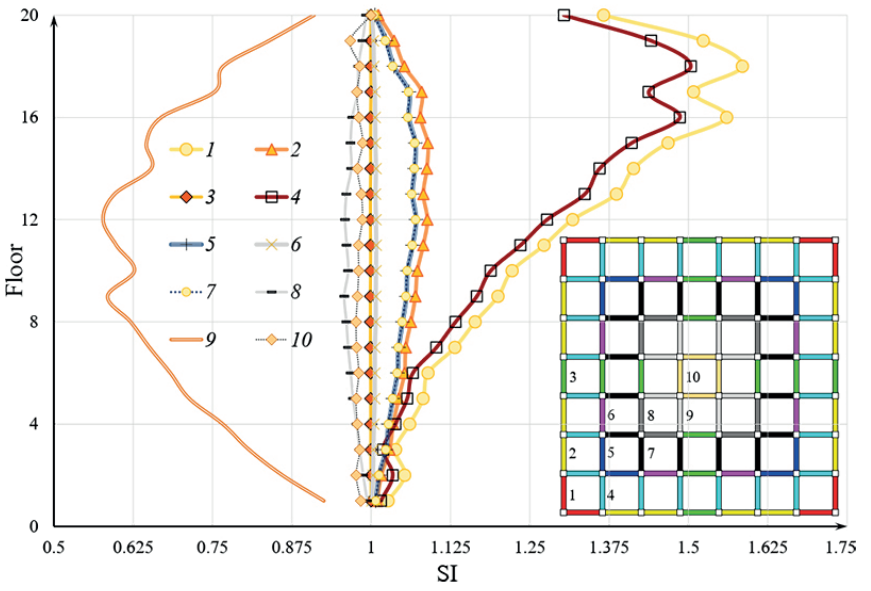

Fig. 4 Sensitivity analysis of beams in model number 5

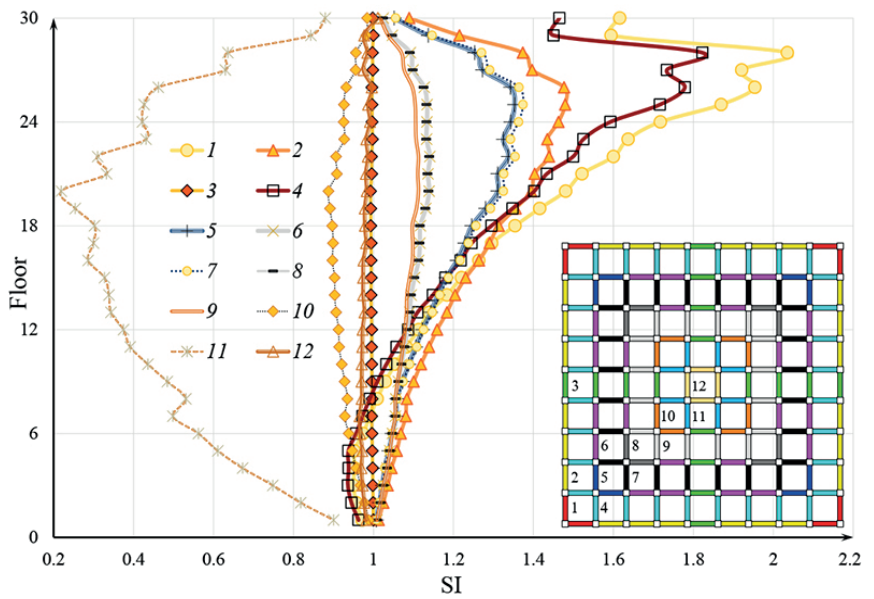

Fig. 5 Sensitivity analysis of beams in model number 7

\section{4 of columns to allocate suggested equations}

The ratio of axial load to maximum axial compressive strength of a column of the first floor according to Eq. (23) is used in order to select appropriate criteria to be able to separate columns with different tributary areas in structural plan.

$$
\mu=P_{u}^{1} / P_{r}^{1}
$$

Where $\left(P_{u}^{1}\right)$ is the axial load caused by load combination of Eq. (21) in column of the first floor of structure caused by conventional one-step analysis and $\left(P_{r}^{1}\right)$ is the axial compressive strength of same column based on Eq. (24).

$$
P_{r}^{1}=0.8 \phi\left[0.85 f_{c}^{\prime}\left(A_{g}-A_{s t}\right)+f_{y} A_{s t}\right]
$$

In which $\left(A_{g}\right)$ is the gross area of column, $\left(A_{s t}\right)$ is the total area of longitudinal reinforcement, $\left(f_{y}\right)$ is the yield strength of longitudinal reinforcement and $(\phi)$ is the strength reduction factor based on ACI318-14 regulations which will be equal to 0.65 for structures of this study. Observation of the calculated values of $\mu$ for all the first floor columns of 9 evaluated models indicate the possibility of classification of columns in three determined categories. Each of the three mentioned categories includes a range of different values of $\mu$ with different upper and lower bounds in structures with 10, 20 and 30 floors. Since the objective of the present research is providing equations for 


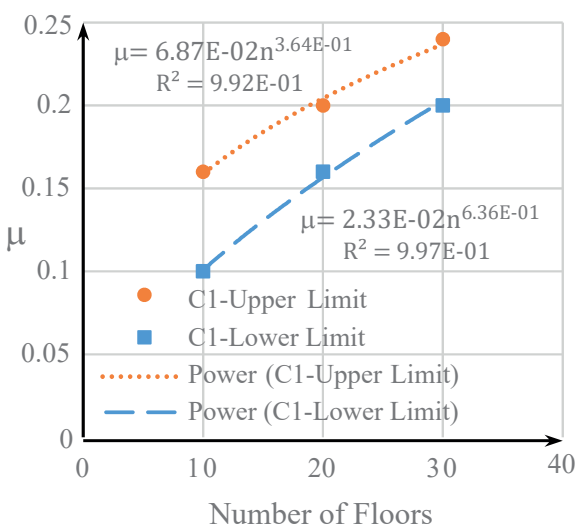

(a)

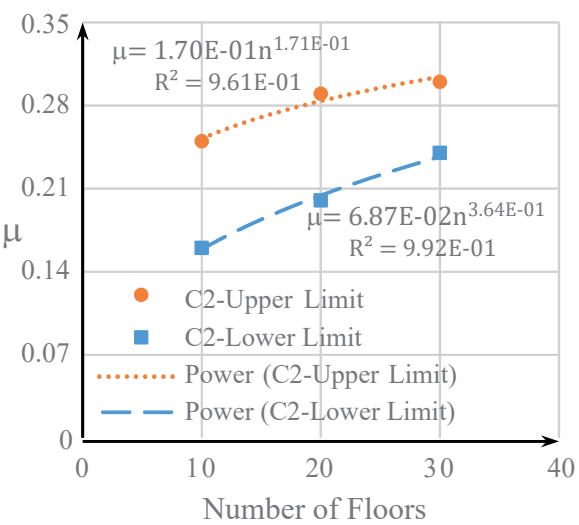

(b)

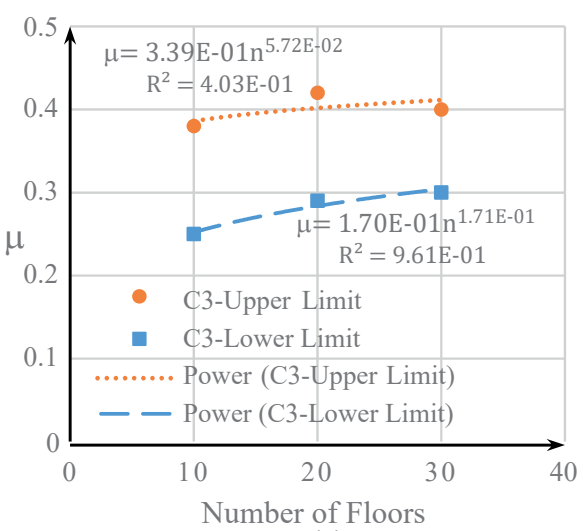

(c)

Fig. 6 Determination of the using range of proposed equations of shortening for a) column type 1, b) column type 2 and c) column type 3

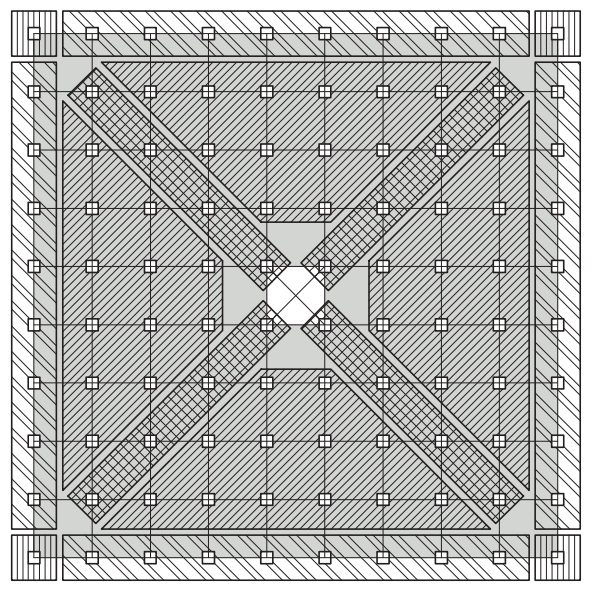

Column Type

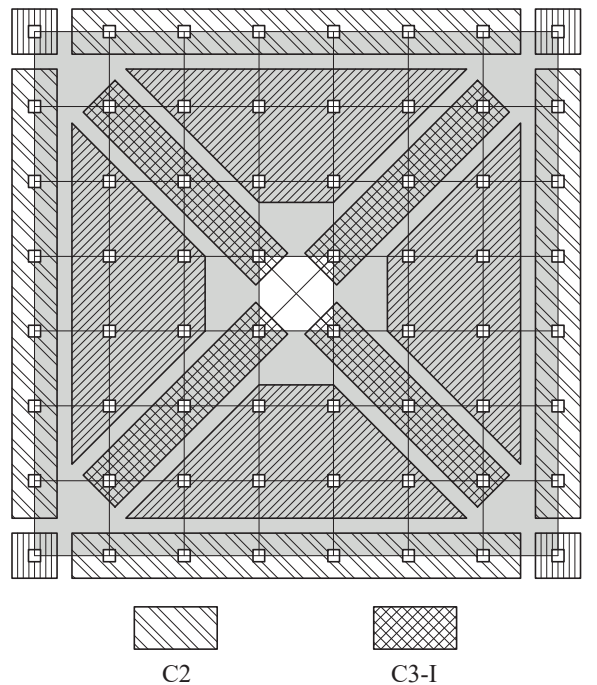

$\mathrm{C} 2$
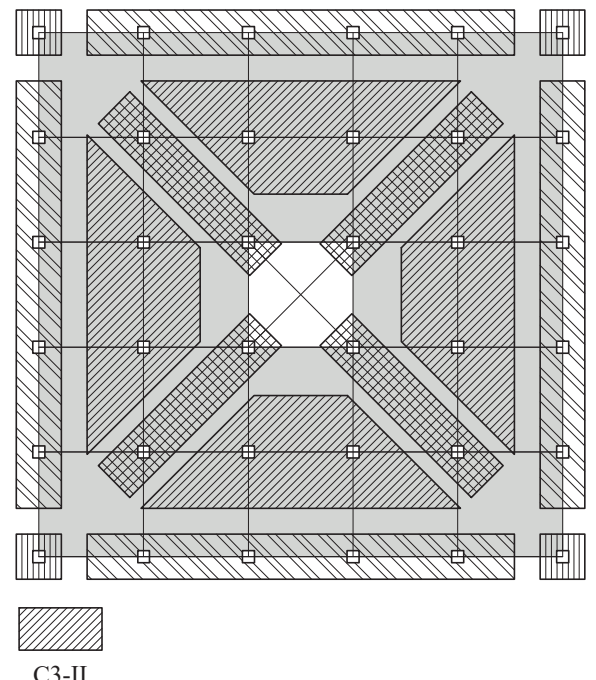

Fig. 7 Ultimate classification of columns in plan

shortening of columns of all special moment frame structures up to 30 floors, equations with specific intervals in terms of number of floors are obtained for allocation of any desired column to any of the three defined column categories as shown in Fig. 6 by drawing upper and lower bounds for each of three mentioned unique category and fitting the best curve which passes the mentioned values for structures with 10, 20 and 30 floors.

According to Fig. 6, Eq. (25), Eq. (26) and Eq. (27) are presented respectively for column type 1 , type 2 and type 3 , based on fitting made for consideration of all framed structures with up to 30 floors.

$$
\begin{array}{ll}
0.0233(n)^{0.636} \leq \mu \leq 0.0687(n)^{0.364} & \Rightarrow C 1 \\
0.0687(n)^{0.364}<\mu \leq 0.17(n)^{0.171} & \Rightarrow C 2 \\
0.17(n)^{0.171}<\mu \leq 0.339(n)^{0.0572} & \Rightarrow C 3
\end{array}
$$

In which $(n)$ is the number of floors in structure. Type of column for using the proposed equations of the present study is determined by calculation of $\mu$ for any desired column of the first floor of each conventionally designed model by placement in the range of Eq. (25) to Eq. (27). Nonlinear staged analyses of all evaluated models for third column type showed that shortening of all columns in mentioned type is not the same despite having the same values of $\mu$ and it can be divided into two categories of C3-I (column located on the diameter of structural plan) and C3-II (other type 3 columns). So, there are ultimately 4 evaluated categories for allocation of long-term shortening equations according to Fig. 7.

\subsection{Sensitivity of long-term inelastic strains of evaluated structures to the number of floors}

The results of detailed nonlinear staged analyses of models have been used for determination of sensitivity level of longterm shortening of all defined column types to the number of floors in each structure. In other words, the objective is measurement of the percentage change of time-dependent staged shortening of different types of columns compared to corresponding values obtained from conventional one-step analysis by increasing the number of floors in structure.

For this purpose, $\xi$ parameter is defined in form of percentage change of staged axial strain (with long-term effects of concrete, $\varepsilon_{N S A}$ ) of each particular column compared to conventional axial strain (without long-term effects of concrete, $\varepsilon_{C A}$ ) according to Eq. (28).

$$
\xi=\left(\frac{\varepsilon_{N S A}-\varepsilon_{C A}}{\varepsilon_{C A}}\right) \times 100
$$


The result of calculation of $\xi$ for $\mathrm{C} 1, \mathrm{C} 2$ and $\mathrm{C} 3$ columns of all evaluated models in different plans considered in the present research have been shown in Fig. 8. As it can be seen, method of growth of $\xi$ values with increase in number of floors have been shown for all 9 sections of Fig. 8 by best fitting of passing curve through $\xi$ values at the top floor of each structure and related equations are reported.

The advantage of doing this is the possibility of finding a boundary for the number of structure floors that passing it will significantly increase the sensitivity of structure to staged shortening in addition to observe the growth of the highest percentage of axial strain changes occurred in different floors of each structure. Determination of floor sensitivity boundary is done by considering $\xi$ to be equal to zero in each of the equations of the relevant part of Fig. 8.
The mentioned values which have been determined by black mark in each part of Fig. 8, show that there are different levels of floor sensitivity in each structure based on different conditions but structures with more than 10 floors can be considered as structures sensitive to staged shortening with reasonable approximation in most models.

\section{Determination of simple equations to predict the long-term behavior of column 3.1 Algorithm of extracting proposed equations}

Algorithm in Fig. 9 has been used to obtain simple equations to predict the long-term behavior of columns in special moment resisting frame structures.

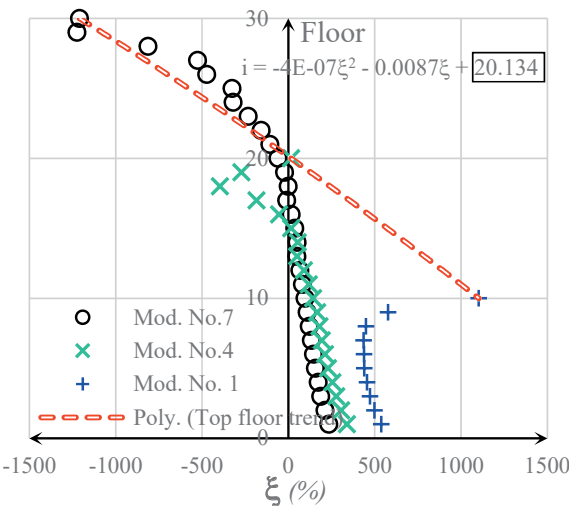

Plan A, C1

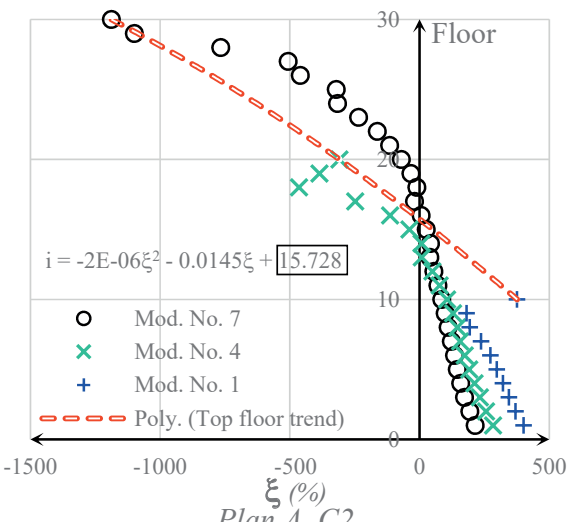

Plan $A, C 2$

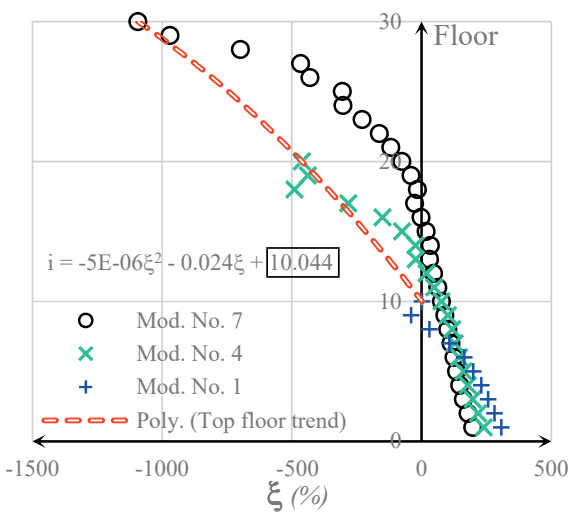

Plan A, C3-I \& C3-II

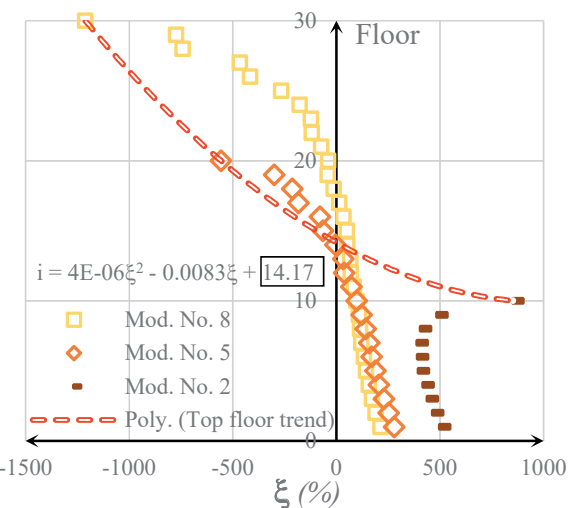

Plan $B, C l$
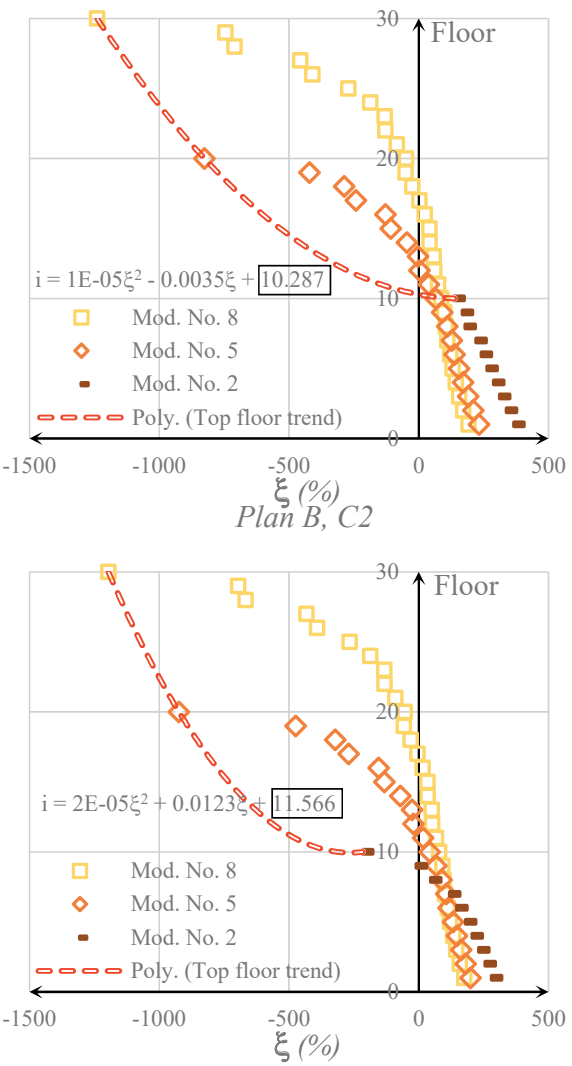

Plan B, C3-I \& C3-II

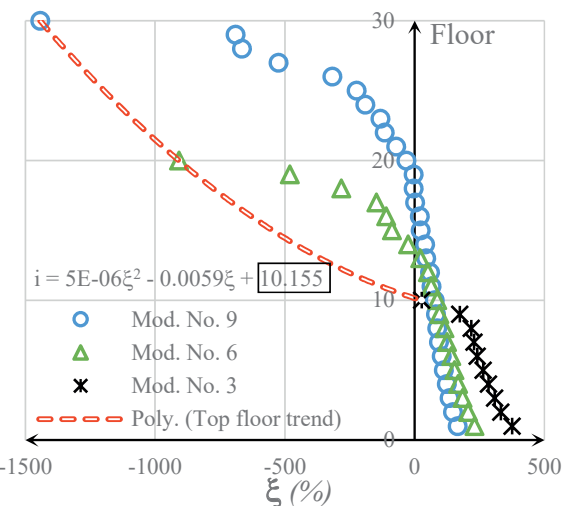

Plan $C, C 1$
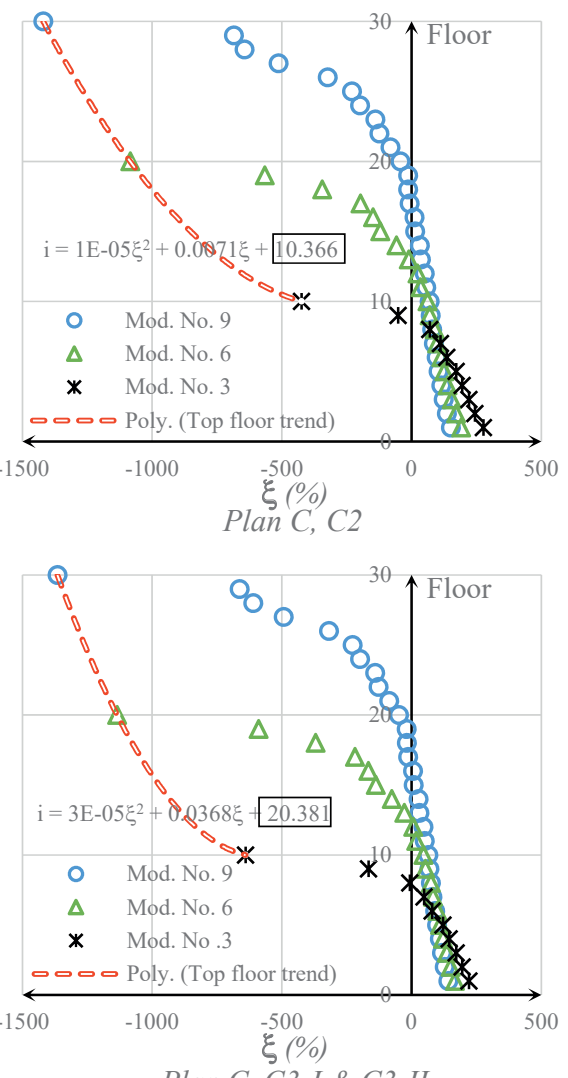

Plan C, C3-I \& C3-II

Fig. 8 Values of in different floors of evaluated models for column C1, C2 and C3-I \& C3-II 


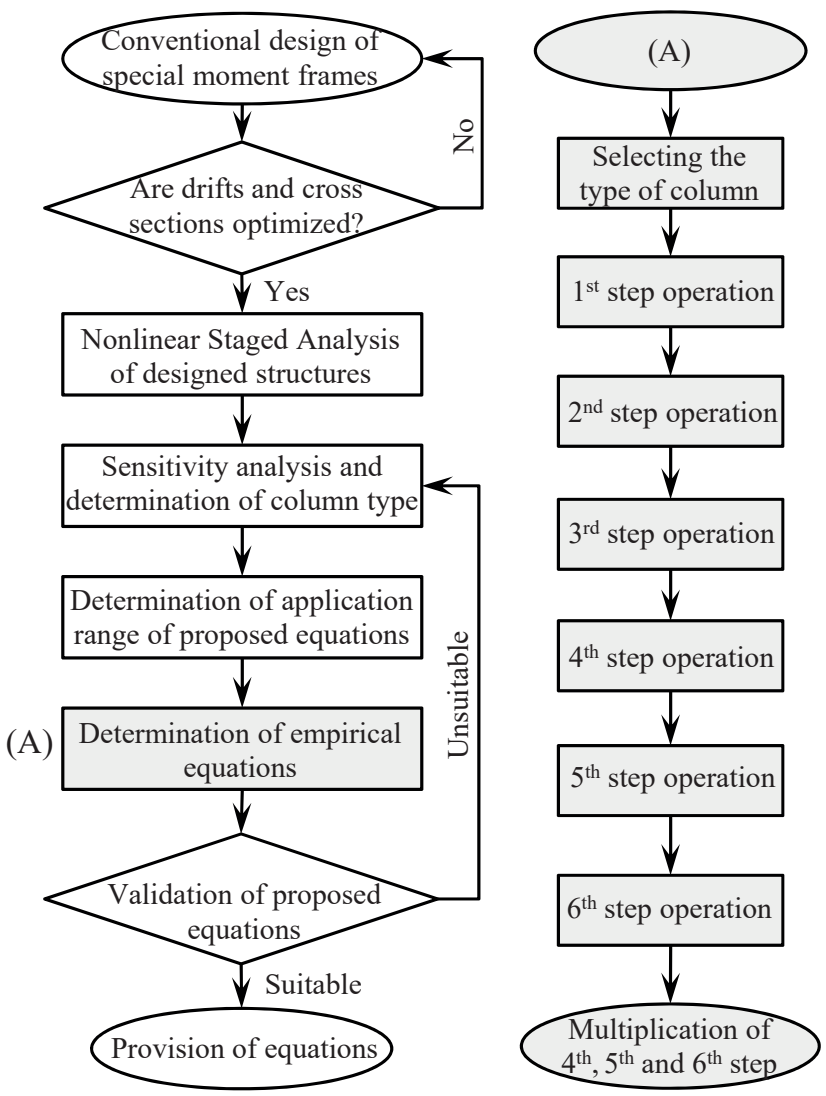

Fig. 9 Algorithm of extracting proposed simple equations of the present study

Operations related to steps 1 to 6 in Fig. 9 are as follows:

$1^{\text {st }}$ step operation: the average value of shortening due to creep (shrinkage, elastic) in all columns of selected column type will be obtained in this step and only a series of shortening data is formed for each one of 9 evaluated models.

$2^{\text {nd }}$ step operation: an average of results obtained from the first step in three A, B and C plans in structures with 10 floors is obtained in this step and the number of 9 series of shortening data in the first step for intended column type is summarized to 3 data series by repeating this for structures with 20 and 30 floors. The effect of span's length will be temporarily ignored by the end of this step.

$3^{\text {rd }}$ step operation: the curve of shortening values resulting from second step are drawing for cases with 10, 20 and 30 floors along with fitting the best curve passing each one of them. ruling equations of each one will be determined in this step.

$4^{\text {th }}$ step operation: the overall equation ruling 3 equations obtained from $3^{\text {rd }}$ step will be determined in this step using trial and error to find the best fit possible. In this way, constant coefficients of equations in $3^{\text {rd }}$ step will be converted to functions of number of structural floors in the final equation. The final equation is a only a function of floor number and number of floors of structure will be stored at the end of this step as the effect factor of floors' number in estimation of creep (shrinkage, elastic) shortening.

$5^{\text {th }}$ step operation: the effect of span length will be applied to the proposed equation in this step with a reversed process compared to $2^{\text {nd }}$ step. For this purpose, the values obtained from $4^{\text {th }}$ step in each of the models with 10, 20 and 30 floors will be compared with average shortening values obtained from $1^{\text {st }}$ step initially in type A plan and the numerical difference in each floor will be determined in form of a function of floor number and number of floors. 3 equations will be determined for each span length by repeating the mentioned process for structures with 10, 20 and 30 floors in type B and then type $\mathrm{C}$ plans. The overall equation ruling the three mentioned equations which is a function of floor number, number of floors and span length will be contained and stored at the end of this step by performing an operation similar to $4^{\text {th }}$ step.

$6^{\text {th }}$ step operation: the direct effect of column length (floor height) will be applied to obtained shortening values using $\left(h_{i} / 3.5\right)$ factor. $\left(h_{i}\right)$ is the height of floor in meters.

The following sections is about the implementation of algorithm in Fig. 9 and different steps of operation for example for creep shortening of type $\mathrm{Cl}$ column.

With regard to the fact that creep shortening values obtained from nonlinear staged analysis of 4 columns in $\mathrm{C} 1$ type in each one of 9 evaluated models are equal, the $1^{\text {st }}$ step of operation is ignored. The results obtained from average of shortening values in $\mathrm{A}, \mathrm{B}$ and $\mathrm{C}$ models in each of the models with 10, 20 and 30 floors ( $2^{\text {nd }}$ step) have been drawn in accordance with Fig. 10 and equations ruling each one of them are selected in form of $3^{\text {rd }}$ degree polynomial ( $3^{\text {rd }}$ step).

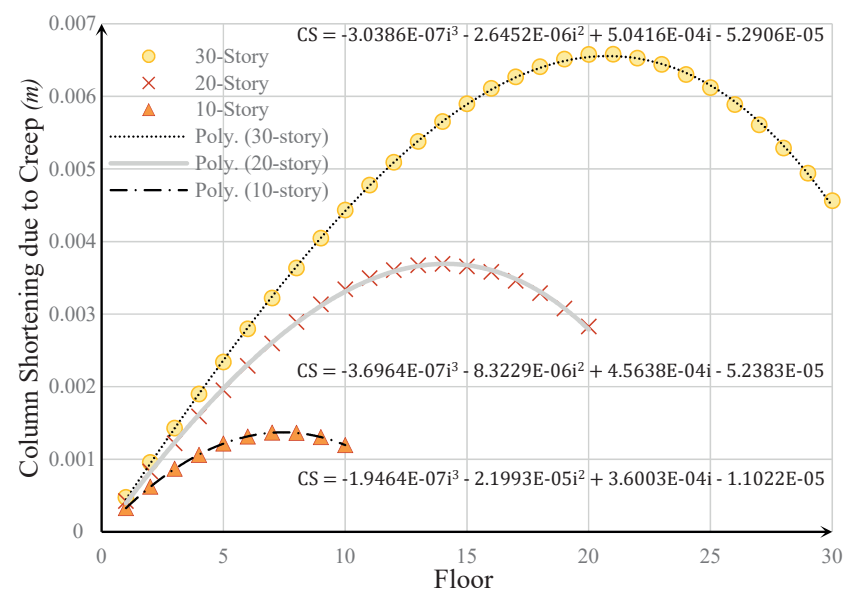

Fig. 10 The results of $3^{\text {rd }}$ step of operation for creep shortening of $\mathrm{C} 1$ column

Creep shortening equation ruling 3 equations in Fig. 10 will be provided for applying the effect of number of floors of structure in accordance with Eq. (29) after Completion of $4^{\text {th }}$ step.

$$
\left(C S_{C 1}\right)_{\text {Creep }}=A i^{3}+B i^{2}+C i+D
$$

In which;

$$
\left\{\begin{array}{l}
A=1.2039 \times 10^{-9} n^{2}-5.3617 \times 10^{-8} n+2.2114 \times 10^{-7} \\
B=-3.9962 \times 10^{-8} n^{2}+2.5659 \times 10^{-6} n-4.3656 \times 10^{-5} \\
C=-2.4285 \times 10^{-7} n^{2}+1.6920 \times 10^{-5} n+2.1511 \times 10^{-4} \\
D=2.0419 \times 10^{-7} n^{2}-1.0262 \times 10^{-5} n+7.1177 \times 10^{-5}
\end{array}\right.
$$


It is obvious that placing 10, 20 and 30 instead of $(n)$ in Eq. (30) will lead to formation of 3 initial equations in Fig. 10. After the division of actual shortening values of selected column type obtained from nonlinear staged analysis $\left(f_{N S A}\right)$ on corresponding values obtained from Eq. (29) $\left(f_{E q .29}\right)$ in each one of models with 10, 20 and 30 floors in type A plan and having the obtained values drawn in diagram, $\left(\chi=f_{N S A} / f_{E q .29}\right)$ the initial equations in which the effect of obtaining average in $2^{\text {nd }}$ step will be neutralized with multiplying them by values of Eq. (29) will be obtained for each one of models with 10, 20 and 30 floors in type A plan according to Fig. 11. It should be noted that in case of performing operations in the $1^{\text {st }}$ step and calculation of average shortening values of all columns in selected column type, values selected for this step ( $5^{\text {th }}$ step) will be defined in form of $\left(\chi=f_{1 s t \text { Step }} / f_{E q .29}\right)$.

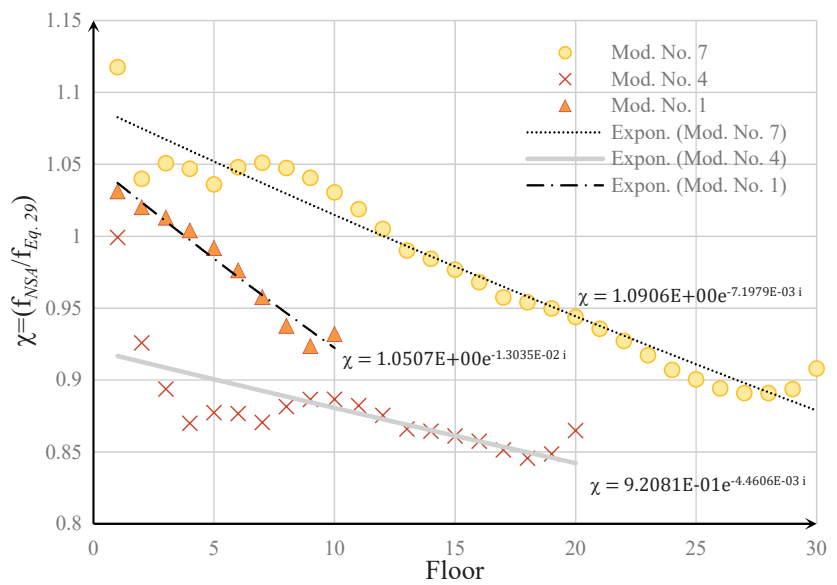

Fig. 11 Operation in the fifth step for estimation of creep shortening in $\mathrm{C} 1$ column in plan type A

The overall equation ruling three mentioned equations will be provided according to Eq. (31) by performing appropriate fitting.

$$
\left(C S_{C 1}\right)_{\text {Creep }}=G \exp (H \times i)
$$

In which $\mathrm{G}$ and $\mathrm{H}$ coefficients are suggested with 2 nd degree polynomials in form of Eq. (32).

$$
\left\{\begin{array}{l}
G=a n^{2}+b n+c \\
H=d n^{2}+e n+f
\end{array}\right.
$$

(a) to $(f)$ coefficients of Eq. (32) will be calculated in form of polynomial $2^{\text {nd }}$ degree functions according to series of Eq. (33) by repeating mentioned process in case of type A plan for B and $\mathrm{C}$ plans and the effect of different dimensions of span in mentioned plans will be reflected in equations ( $5^{\text {th }}$ step of operation).

$$
\left\{\begin{array}{l}
a=1.2139 \times 10^{-3} l^{2}-1.3689 \times 10^{-2} l+3.6374 \times 10^{-2} \\
b=-4.9882 \times 10^{-2} l^{2}+5.6016 \times 10^{-1} l-1.482 \\
c=4.6342 \times 10^{-1} l^{2}-5.1598 l+1.4538 \times 10^{+1} \\
d=-5.1167 \times 10^{-5} l^{2}+5.7536 \times 10^{-4} l-1.5202 \times 10^{-3} \\
e=2.0468 \times 10^{-3} l^{2}-2.3223 \times 10^{-2} l+6.1912 \times 10^{-2} \\
f=-1.8077 \times 10^{-2} l^{2}+2.1193 \times 10^{-1} l-5.8369 \times 10^{-1}
\end{array}\right.
$$

It is noteworthy that placing 10,20 and 30 instead of (n) for span dimension of plan $\mathrm{A}(l=3.889 \mathrm{~m})$ in Eq. (32) and Eq. (33) leads to 3 initial equations in Fig. 11 with very acceptable approximation. The final equation for estimation of shortening due to creep in column type $\mathrm{Cl}$ will be the product of Eq. (29) and Eq. (31) and the effect of floor height ( $6^{\text {th }}$ step operation) in form of $\left(h_{i} / 3.5\right)$.

\subsection{Presenting the final proposed equations}

The simple proposed equations of the present research for shortening due to creep, shrinkage and time changes of modulus of elasticity of columns in terms of meters have been presented respectively in from form of Eq. (34), Eq. (35) and Eq. (36) using the raised algorithm (Fig. 9) for long-term behavior of moment resisting frame structures with conventional and optimized design based on ACI318-14 regulations.

$$
\begin{gathered}
C S_{\text {Creep }}\left(i, h_{i}, n, l\right)=\left(A i^{3}+B i^{2}+C i+D\right) \cdot G \exp (H \cdot i) \cdot\left(h_{i} / 3 \cdot 5\right) \\
C S_{\text {Elastic }}\left(i, h_{i}, n, l\right)=\left(A i^{3}+B i^{2}+C i+D\right) \cdot G \exp (H \cdot i) \cdot\left(h_{i} / 3.5\right) \\
C S_{\text {Shrinkage }}\left(i, h_{i}, n, l\right)=\left(E i^{F}\right) \cdot(G \cdot \operatorname{Ln}(i)+H) \cdot\left(h_{i} / 3 \cdot 5\right)
\end{gathered}
$$

In which;

$$
\left\{\begin{array}{l}
A=a_{1} n^{2}+b_{1} n+c_{1} \\
B=d_{1} n^{2}+e_{1} n+f_{1} \\
C=g_{1} n^{2}+h_{1} n+i_{1} \\
D=j_{1} n^{2}+k_{1} n+l_{1} \\
E=m_{1} \exp \left(n_{1} \cdot n\right) \\
F=o_{1} n^{p_{1}} \\
G=\left(a_{2} l^{2}+b_{2} l+c_{2}\right) n^{2}+\left(d_{2} l^{2}+e_{2} l+f_{2}\right) n+\left(g_{2} l^{2}+h_{2} l+i_{2}\right) \\
H=\left(j_{2} l^{2}+k_{2} l+l_{2}\right) n^{2}+\left(m_{2} l^{2}+n_{2} l+o_{2}\right) n+\left(p_{2} l^{2}+q_{2} l+r_{2}\right)
\end{array}\right.
$$

Variables in above equations are floor number $(i)$, span length $(l)$, height of $i$-th floor $\left(h_{i}\right)$ and number of floors in structure $(n)$ and other parameters are constant coefficients with values listed in Table 6, Table 7, Table 8 and Table 9 respectively for columns of C1, C2, C3-I and C3-II types. 
Table 6 Constant coefficients of equations (34 to 37) for C1 column

\begin{tabular}{|c|c|c|c|}
\hline Constant & Creep & Elastic & Shrinkage \\
\hline$a_{1}$ & $1.2039 \times 10^{-9}$ & $2.2071 \times 10^{-9}$ & - \\
\hline$b_{1}$ & $-5.3617 \times 10^{-8}$ & $-1.1518 \times 10^{-7}$ & - \\
\hline$c_{1}$ & $2.2114 \times 10^{-7}$ & $1.2646 \times 10^{-6}$ & - \\
\hline$d_{1}$ & $-3.9962 \times 10^{-8}$ & $-4.075 \times 10^{-8}$ & - \\
\hline$e_{1}$ & $2.5659 \times 10^{-6}$ & $2.8332 \times 10^{-6}$ & - \\
\hline$f_{1}$ & $-4.3656 \times 10^{-5}$ & $-5.9804 \times 10^{-5}$ & - \\
\hline$g_{1}$ & $-2.4285 \times 10^{-7}$ & $-2.522 \times 10^{-7}$ & - \\
\hline$h_{1}$ & $1.692 \times 10^{-5}$ & $1.985 \times 10^{-5}$ & - \\
\hline$i_{1}$ & $2.1511 \times 10^{-4}$ & $1.7641 \times 10^{-4}$ & - \\
\hline$j_{1}$ & $2.0419 \times 10^{-7}$ & $1.4002 \times 10^{-7}$ & - \\
\hline$k_{1}$ & $-1.0262 \times 10^{-5}$ & $-9.0974 \times 10^{-6}$ & - \\
\hline$l_{1}$ & $7.1177 \times 10^{-5}$ & $5.9494 \times 10^{-5}$ & - \\
\hline$m_{1}$ & - & - & $1.4645 \times 10^{-3}$ \\
\hline$n_{1}$ & - & - & $-2.2476 \times 10^{-2}$ \\
\hline$o_{1}$ & - & - & $8.6644 \times 10^{-1}$ \\
\hline$p_{1}$ & - & - & $-3.5487 \times 10^{-2}$ \\
\hline$a_{2}$ & $1.2139 \times 10^{-3}$ & $1.1876 \times 10^{-3}$ & $-2.1436 \times 10^{-4}$ \\
\hline$b_{2}$ & $-1.3689 \times 10^{-2}$ & $-1.3366 \times 10^{-2}$ & $2.3584 \times 10^{-3}$ \\
\hline$c_{2}$ & $3.6374 \times 10^{-2}$ & $3.5487 \times 10^{-2}$ & $-6.0309 \times 10^{-3}$ \\
\hline$d_{2}$ & $-4.9882 \times 10^{-2}$ & $-4.8055 \times 10^{-2}$ & $7.939 \times 10^{-3}$ \\
\hline$e_{2}$ & $5.6016 \times 10^{-1}$ & $5.3752 \times 10^{-1}$ & $-8.628 \times 10^{-3}$ \\
\hline$f_{2}$ & -1.482 & -1.4182 & $2.1748 \times 10^{-1}$ \\
\hline$g_{2}$ & $4.6342 \times 10^{-1}$ & $4.3758 \times 10^{-1}$ & $-6.5511 \times 10^{-2}$ \\
\hline$h_{2}$ & -5.1598 & -4.8349 & $7.2712 \times 10^{-1}$ \\
\hline$i_{2}$ & $1.4538 \times 10^{+1}$ & $1.3601 \times 10^{+1}$ & -1.8758 \\
\hline$j_{2}$ & $-5.1167 \times 10^{-5}$ & $-5.9499 \times 10^{-5}$ & $6.5462 \times 10^{-4}$ \\
\hline$k_{2}$ & $5.7536 \times 10^{-4}$ & $6.7489 \times 10^{-4}$ & $-7.3469 \times 10^{-3}$ \\
\hline$l_{2}$ & $-1.5202 \times 10^{-3}$ & $-1.8082 \times 10^{-3}$ & $1.9214 \times 10^{-2}$ \\
\hline$m_{2}$ & $2.0468 \times 10^{-3}$ & $2.3919 \times 10^{-3}$ & $-2.4961 \times 10^{-2}$ \\
\hline$l_{2}$ & $-2.3223 \times 10^{-2}$ & $-2.742 \times 10^{-2}$ & $2.7442 \times 10^{-1}$ \\
\hline $\mathrm{o}_{2}$ & $6.1912 \times 10^{-2}$ & $7.431 \times 10^{-2}$ & $-7.0201 \times 10^{-1}$ \\
\hline$p_{2}$ & $-1.8077 \times 10^{-2}$ & $-2.1632 \times 10^{-2}$ & $2.2211 \times 10^{-1}$ \\
\hline$q_{2}$ & $2.1193 \times 10^{-1}$ & $2.569 \times 10^{-1}$ & -2.5395 \\
\hline$r_{2}$ & $-5.8369 \times 10^{-1}$ & $-7.2054 \times 10^{-1}$ & 7.773 \\
\hline
\end{tabular}

Table 7 Constant coefficients of equations (34 to 37) for C2 column

\begin{tabular}{|c|c|c|c|}
\hline Constant & Creep & Elastic & Shrinkage \\
\hline$a_{1}$ & $1.5043 \times 10^{-9}$ & $3.0256 \times 10^{-9}$ & - \\
\hline$b_{1}$ & $-6.0447 \times 10^{-8}$ & $-1.5221 \times 10^{-7}$ & - \\
\hline$c_{1}$ & $6.7780 \times 10^{-8}$ & $1.5398 \times 10^{-6}$ & - \\
\hline$d_{1}$ & $-6.7041 \times 10^{-8}$ & $-7.135 \times 10^{-8}$ & - \\
\hline$e_{1}$ & $4.1239 \times 10^{-6}$ & $4.8087 \times 10^{-6}$ & - \\
\hline$f_{1}$ & $-6.5402 \times 10^{-5}$ & $-9.2701 \times 10^{-5}$ & - \\
\hline$g_{1}$ & $-4.067 \times 10^{-7}$ & $-4.8985 \times 10^{-7}$ & - \\
\hline$h_{1}$ & $1.9993 \times 10^{-5}$ & $2.6948 \times 10^{-5}$ & - \\
\hline$i_{1}$ & $3.7344 \times 10^{-4}$ & $3.0902 \times 10^{-4}$ & - \\
\hline$j_{l}$ & $3.7045 \times 10^{-7}$ & $3.5156 \times 0^{-7}$ & - \\
\hline$k_{1}$ & $-1.5445 \times 10^{-5}$ & $-1.6214 \times 10^{-5}$ & - \\
\hline$l_{1}$ & $1.0771 \times 10^{-4}$ & $1.1255 \times 0^{-4}$ & - \\
\hline$m_{1}$ & - & - & $1.4723 \times 10^{-3}$ \\
\hline$n_{1}$ & - & - & $-2.2734 \times 10^{-2}$ \\
\hline$o_{1}$ & - & - & $8.6603 \times 10^{-1}$ \\
\hline$p_{1}$ & - & - & $-3.5332 \times 10^{-2}$ \\
\hline$a_{2}$ & $1.1944 \times 10^{-3}$ & $1.1784 \times 10^{-3}$ & $-2.1354 \times 10^{-4}$ \\
\hline$b_{2}$ & $-1.3495 \times 10^{-2}$ & $-1.3289 \times 10^{-2}$ & $2.3499 \times 10^{-3}$ \\
\hline$c_{2}$ & $3.5921 \times 10^{-2}$ & $3.5338 \times 10^{-2}$ & $-6.0094 \times 10^{-3}$ \\
\hline$d_{2}$ & $-4.9345 \times 10^{-2}$ & $-4.8056 \times 10^{-2}$ & $7.901 \times 10^{-3}$ \\
\hline$e_{2}$ & $5.5537 \times 10^{-1}$ & $5.3873 \times 10^{-1}$ & $-8.5869 \times 10^{-2}$ \\
\hline$f_{2}$ & -1.4725 & -1.4241 & $2.1643 \times 10^{-1}$ \\
\hline$g_{2}$ & $4.594 \times 10^{-1}$ & $4.3934 \times 10^{-1}$ & $-6.5123 \times 10^{-2}$ \\
\hline$h_{2}$ & -5.1041 & -4.839 & $7.2291 \times 10^{-1}$ \\
\hline$i_{2}$ & $1.4362 \times 10^{+1}$ & $1.3566 \times 10^{+1}$ & -1.8649 \\
\hline$j_{2}$ & $-5.4434 \times 10^{-5}$ & $-6.3928 \times 10^{-5}$ & $6.5273 \times 10^{-4}$ \\
\hline$k_{2}$ & $6.1182 \times 10^{-4}$ & $7.2131 \times 10^{-4}$ & $-7.3281 \times 10^{-3}$ \\
\hline$l_{2}$ & $-1.6164 \times 10^{-3}$ & $-1.9206 \times 10^{-3}$ & $1.9171 \times 10^{-2}$ \\
\hline$m_{2}$ & $2.204 \times 10^{-3}$ & $2.5914 \times 10^{-3}$ & $-2.4871 \times 10^{-2}$ \\
\hline$l_{2}$ & $-2.4974 \times 10^{-2}$ & $-2.9455 \times 10^{-2}$ & $2.7346 \times 10^{-1}$ \\
\hline $\mathrm{O}_{2}$ & $6.6529 \times 10^{-2}$ & $7.9058 \times 10^{-2}$ & $-6.9936 \times 10^{-1}$ \\
\hline$p_{2}$ & $-1.9889 \times 10^{-2}$ & $-2.3674 \times 10^{-2}$ & $2.2119 \times 10^{-1}$ \\
\hline$q_{2}$ & $2.3214 \times 10^{-1}$ & $2.7682 \times 10^{-1}$ & -2.5294 \\
\hline$r_{2}$ & $-6.3721 \times 10^{-1}$ & $-7.6447 \times 10^{-1}$ & 7.7416 \\
\hline
\end{tabular}


Table 8 Constant coefficients of equations (34 to 37) for C3-I column

\begin{tabular}{|c|c|c|c|}
\hline Constant & Creep & Elastic & Shrinkage \\
\hline$a_{1}$ & $1.8002 \times 10^{-9}$ & $3.9784 \times 10^{-9}$ & - \\
\hline$b_{1}$ & $-6.2903 \times 10^{-8}$ & $-1.9166 \times 10^{-7}$ & - \\
\hline$c_{1}$ & $-2.3266 \times 10^{-7}$ & $1.7287 \times 10^{-6}$ & - \\
\hline$d_{1}$ & $-1.08 \times 10^{-7}$ & $-1.203 \times 10^{-7}$ & - \\
\hline$e_{1}$ & $6.4051 \times 10^{-6}$ & $7.8217 \times 10^{-6}$ & - \\
\hline$f_{1}$ & $-9.5914 \times 10^{-5}$ & $-1.3974 \times 10^{-4}$ & - \\
\hline$g_{1}$ & $-5.645 \times 10^{-7}$ & $-7.6275 \times 10^{-7}$ & - \\
\hline$h_{1}$ & $2.0268 \times 10^{-5}$ & $3.2908 \times 10^{-5}$ & - \\
\hline$i_{1}$ & $6.2726 \times 10^{-4}$ & $5.304 \times 10^{-4}$ & - \\
\hline$j_{I}$ & $5.7957 \times 10^{-7}$ & $6.1693 \times 10^{-7}$ & - \\
\hline$k_{1}$ & $-2.1434 \times 10^{-5}$ & $-2.4154 \times 10^{-5}$ & - \\
\hline$l_{1}$ & $1.5355 \times 10^{-4}$ & $1.7605 \times 10^{-4}$ & - \\
\hline$m_{1}$ & - & - & $1.4723 \times 10^{-3}$ \\
\hline$n_{1}$ & - & - & $-2.2736 \times 10^{-2}$ \\
\hline$o_{1}$ & - & - & $8.6593 \times 10^{-1}$ \\
\hline$p_{1}$ & - & - & $-3.5283 \times 10^{-2}$ \\
\hline$a_{2}$ & $1.1761 \times 10^{-3}$ & $1.1617 \times 10^{-3}$ & $-2.1356 \times 10^{-4}$ \\
\hline$b_{2}$ & $-1.3306 \times 10^{-2}$ & $-1.3123 \times 10^{-2}$ & $2.3501 \times 10^{-3}$ \\
\hline$c_{2}$ & $3.5459 \times 10^{-2}$ & $3.4946 \times 10^{-2}$ & $-6.0107 \times 10^{-3}$ \\
\hline$d_{2}$ & $-4.8774 \times 10^{-2}$ & $-4.7655 \times 10^{-2}$ & $7.9019 \times 10^{-3}$ \\
\hline$e_{2}$ & $5.5045 \times 10^{-1}$ & $5.3591 \times 10^{-1}$ & $-8.588 \times 10^{-2}$ \\
\hline$f_{2}$ & -1.4634 & -1.4209 & $2.1648 \times 10^{-1}$ \\
\hline$g_{2}$ & $4.5297 \times 10^{-1}$ & $4.3519 \times 10^{-1}$ & $-6.5103 \times 10^{-2}$ \\
\hline$h_{2}$ & -5.0458 & -4.8071 & $7.2269 \times 10^{-1}$ \\
\hline$i_{2}$ & $1.4244 \times 10^{+1}$ & $1.3519 \times 10^{+1}$ & -1.8645 \\
\hline$j_{2}$ & $-5.6614 \times 10^{-5}$ & $-6.5997 \times 10^{-5}$ & $6.5263 \times 10^{-4}$ \\
\hline$k_{2}$ & $6.3606 \times 10^{-4}$ & $7.4265 \times 10^{-4}$ & $-7.3271 \times 10^{-3}$ \\
\hline$l_{2}$ & $-1.68 \times 10^{-3}$ & $-1.971 \times 10^{-3}$ & $1.917 \times 10^{-2}$ \\
\hline$m_{2}$ & $2.3108 \times 10^{-3}$ & $2.6865 \times 10^{-3}$ & $-2.487 \times 10^{-2}$ \\
\hline$l_{2}$ & $-2.6156 \times 10^{-2}$ & $-3.0397 \times 10^{-2}$ & $2.7345 \times 10^{-1}$ \\
\hline $\mathrm{o}_{2}$ & $6.9621 \times 10^{-2}$ & $8.1157 \times 10^{-2}$ & $-6.9941 \times 10^{-1}$ \\
\hline$p_{2}$ & $-2.1148 \times 10^{-2}$ & $-2.4659 \times 10^{-2}$ & $2.2112 \times 10^{-1}$ \\
\hline$q_{2}$ & $2.46 \times 10^{-1}$ & $2.8574 \times 10^{-1}$ & -2.5286 \\
\hline$r_{2}$ & $-6.7318 \times 10^{-1}$ & $-7.8164 \times 10^{-1}$ & 7.7404 \\
\hline
\end{tabular}

Table 9 Constant coefficients of equations (34 to 37) for C3-II column

\begin{tabular}{|c|c|c|c|}
\hline Constant & Creep & Elastic & Shrinkage \\
\hline$a_{1}$ & $1.6721 \times 10^{-9}$ & $3.9282 \times 10^{-9}$ & - \\
\hline$b_{1}$ & $-5.3662 \times 10^{-8}$ & $-1.8604 \times 10^{-7}$ & - \\
\hline$c_{1}$ & $-4.0609 \times 10^{-7}$ & $1.5796 \times 10^{-6}$ & - \\
\hline$d_{1}$ & $-1.1399 \times 10^{-7}$ & $-1.2972 \times 10^{-7}$ & - \\
\hline$e_{1}$ & $6.7054 \times 10^{-6}$ & $8.3593 \times 10^{-6}$ & - \\
\hline$f_{1}$ & $-9.9263 \times 10^{-5}$ & $-1.4698 \times 10^{-4}$ & - \\
\hline$g_{1}$ & $-5.682 \times 10^{-7}$ & $-7.945 \times 10^{-7}$ & - \\
\hline$h_{1}$ & $1.9124 \times 10^{-5}$ & $3.2684 \times 10^{-5}$ & - \\
\hline$i_{1}$ & $6.7415 \times 10^{-4}$ & $5.7861 \times 10^{-4}$ & - \\
\hline$j_{1}$ & $6.0367 \times 10^{-7}$ & $6.6758 \times 10^{-7}$ & - \\
\hline$k_{1}$ & $-2.1862 \times 10^{-5}$ & $-2.5316 \times 10^{-5}$ & - \\
\hline$l_{1}$ & $1.5913 \times 10^{-4}$ & $1.877 \times 10^{-4}$ & - \\
\hline$m_{1}$ & - & - & $1.4725 \times 10^{-3}$ \\
\hline$n_{1}$ & - & - & $-2.2744 \times 10^{-2}$ \\
\hline$o_{1}$ & - & - & $8.6574 \times 10^{-1}$ \\
\hline$p_{1}$ & - & - & $-3.5212 \times 10^{-2}$ \\
\hline$a_{2}$ & $1.1626 \times 10^{-3}$ & $1.1513 \times 10^{-3}$ & $-2.1345 \times 10^{-4}$ \\
\hline$b_{2}$ & $-1.3148 \times 10^{-2}$ & $-1.2998 \times 10^{-2}$ & $2.3492 \times 10^{-3}$ \\
\hline$c_{2}$ & $3.5023 \times 10^{-2}$ & $3.4595 \times 10^{-2}$ & $-6.0084 \times 10^{-3}$ \\
\hline$d_{2}$ & $-4.8219 \times 10^{-2}$ & $-4.7288 \times 10^{-2}$ & $7.8975 \times 10^{-3}$ \\
\hline$e_{2}$ & $5.4366 \times 10^{-1}$ & $5.3107 \times 10^{-1}$ & $-8.5843 \times 10^{-2}$ \\
\hline$f_{2}$ & -1.4439 & -1.4062 & $2.1638 \times 10^{-1}$ \\
\hline$g_{2}$ & $4.4821 \times 10^{-1}$ & $4.3322 \times 10^{-1}$ & $-6.508 \times 10^{-2}$ \\
\hline$h_{2}$ & -4.9758 & -4.7641 & $7.225 \times 10^{-1}$ \\
\hline$i_{2}$ & $1.4015 \times 10^{+1}$ & $1.335 \times 10^{+1}$ & -1.8639 \\
\hline$j_{2}$ & $-5.6479 \times 10^{-5}$ & $-6.6281 \times 10^{-5}$ & $6.5264 \times 10^{-4}$ \\
\hline$k_{2}$ & $6.3489 \times 10^{-4}$ & $7.4576 \times 10^{-4}$ & $-7.3282 \times 10^{-3}$ \\
\hline$l_{2}$ & $-1.6781 \times 10^{-3}$ & $-1.9794 \times 10^{-3}$ & $1.9172 \times 10^{-2}$ \\
\hline$m_{2}$ & $2.3057 \times 10^{-3}$ & $2.701 \times 10^{-3}$ & $-2.4869 \times 10^{-2}$ \\
\hline$l_{2}$ & $-2.6122 \times 10^{-2}$ & $-3.0564 \times 10^{-2}$ & $2.7347 \times 10^{-1}$ \\
\hline$o_{2}$ & $6.9613 \times 10^{-2}$ & $8.1622 \times 10^{-2}$ & $-6.9944 \times 10^{-1}$ \\
\hline$p_{2}$ & $-2.1107 \times 10^{-2}$ & $-2.4819 \times 10^{-2}$ & $2.2112 \times 10^{-1}$ \\
\hline$q_{2}$ & $2.4596 \times 10^{-1}$ & $2.8784 \times 10^{-1}$ & -2.5288 \\
\hline$r_{2}$ & $-6.7454 \times 10^{-1}$ & $-7.8842 \times 10^{-1}$ & 7.7406 \\
\hline
\end{tabular}


As it can be seen in Tables (6 to 9), the shrinkage constants of all types of defined columns are almost equal. The approximate similarity of proposed shrinkage coefficients for both $\left(m_{1}\right.$ to $\left.p_{1}\right)$ and $\left(a_{2}\right.$ to $\left.r_{2}\right)$ shows that the proposed equation for shrinkage is independent from situation and tributary area of column and each one of specific proposed series of shrinkage constants can be used to predict the shrinkage behavior of all types of columns with a very good approximation.

\section{Verification of the proposed equations}

As it was already mentioned, the application of proposed equations in the present study is in range of structures with up to 30 floors for special reinforced concrete moment resisting frames. The mentioned range is a range of frame structures in which designing of structure with the moment frame system is usually economically justified and basically, other structural systems must be used for higher structures due to large cross sections of structural elements to withstand the lateral loads. Hence, the main focus of this article in discussion about validation of results was also in the mentioned range for floors. Re-modeling with different geometric characteristics (dimensions of span, height of floor and number of floors in structure) from productive models of proposed equations has been carried out for validation of proposed equations. In addition, the modeling of structures with more than 30 floors has also been carried out in order to test the proposed equation out of the mentioned range for floors which will be discussed in the following section.

\subsection{Special concrete moment frame structures with up to 30 floors}

Since the geometric variables reflected in proposed equations (34 to 37) are span length, height and number of floors of structure, three test models with the numbers of 1, 2 and 3 have been selected with following specifications for validation of the proposed equations. The validation of equations provided for column $\mathrm{C} 1$ caused only by the effect of changing the number of floors will be evaluated in test model number 1 with 16 floors and span length of 7 meters and story height of 3.5 meters.

Test model number 2 with 24 floors and span length of 5 meters and story height of 4 meters tests the effect of simultaneous change in height and number of floors of the structure for validation of shortening equations in column C3-II and Test model number 3 with 28 floors and span length of 6 meters and story height of 3.8 meters evaluates the equations provided for column C3-I under changes of all three geometric variables in mentioned equations. The results of optimum and conventional design of three mentioned models for sections of structural elements have been shown in Fig. 12.
As it can be seen in Fig. (12) one column of C1, C3-II and C3-I type has been selected from the plan of each test model $(1,2$ and 3$)$ in accordance with Fig. 7 for validation. Values of $\mu$ for columns of test models number 1, 2 and 3 based on Eq. (23) are respectively $0.159,0.364$ and 0.355 . With respect to the number of floors in mentioned models which are 16, 24 and 28, the column selected for test model number 1 is in range of Eq. (25) and columns selected for test models number 2 and 3 are in range of Eq. (27) which prove the validity of equations (25 to 27). Results of detailed nonlinear staged analysis of validation models and corresponding values obtained from simple equations proposed in research for creep, shrinkage and elastic shortenings of each one of test models number 1, 2 and 3 have been respectively shown in Fig. 13, Fig. 14 and Fig. 15.

As it can be observed in Figures (13 to 15), the proposed equations evaluate long term shortenings of columns with average error less than 2 percent for all values in best and easiest way possible and have carried out the estimations almost identical to exact values and this proves the possibility of final provision of all three equations (34 to 36) for frame structures with up to 30 floors.

\subsection{Special concrete moment frame structures with more than $\mathbf{3 0}$ floors}

Two test models with number 4 and 5 respectively with 32 and 40 floors have been considered for validation of proposed equations for shortening in structures out of the range of 30 floors. Test model number 4 with 32 floors and span length of 6 meters and floor height of 3.8 meters and test model number 5 with 40 floors and span length of 6 meters and floor height of 3 meters respectively verify the validity of proposed equations for shortening of C3-I and C2 columns. Plan of structures and the results obtained from the optimized designing based on conventional analysis of two mentioned models for sections of structural elements have been shown in Fig. 12.

Results obtained from detailed nonlinear staged analysis of two evaluated models and corresponding values obtained from simple proposed equations of the present study show that the proposed equations for creep and elastic shortenings have led to considerable error for the corresponding models especially for model number 5 (with 40 floors). hence, the use of Eq. (34) and Eq. (35) is not recommended for frame structures taller than 30 floors at all. But, Eq. (36), has estimated shortening caused by shrinkage of columns with an excellent approximation as shown in Fig. (16) with an average error of less than 1.3 and 11.7 percent compared to exact values of nonlinear staged analysis of test models number 4 and 5, respectively. This indicates the correctness of Eq. (36) even for structures taller than 30 floors and its capability for all high-rise frame structures. 

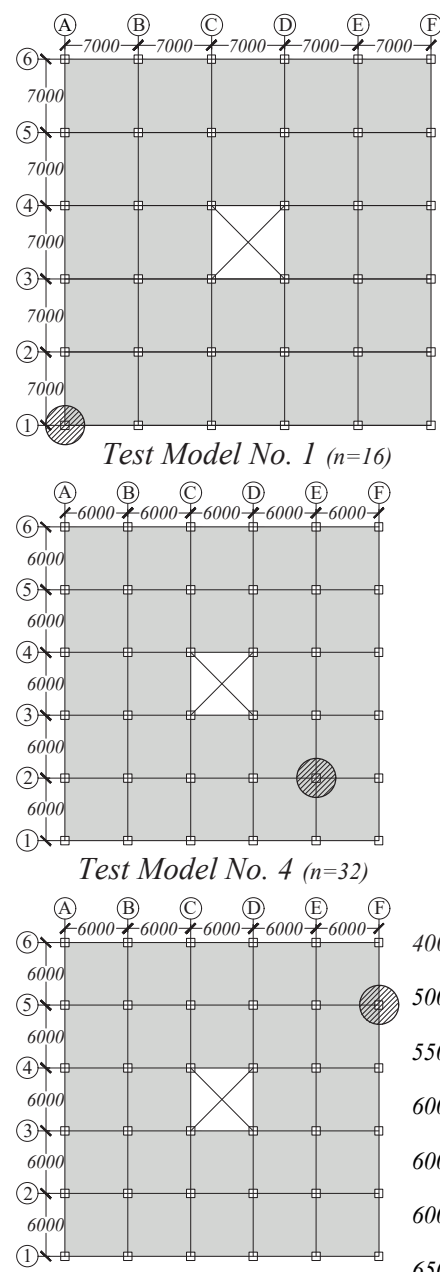

Test Model No. 5 ( $n=40)$

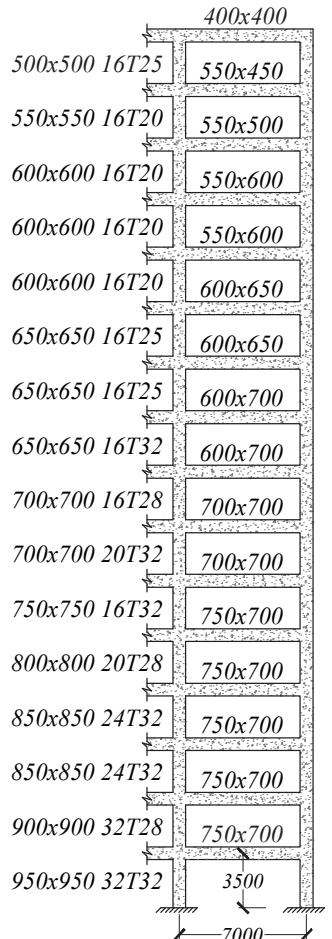

Test Model No. 1
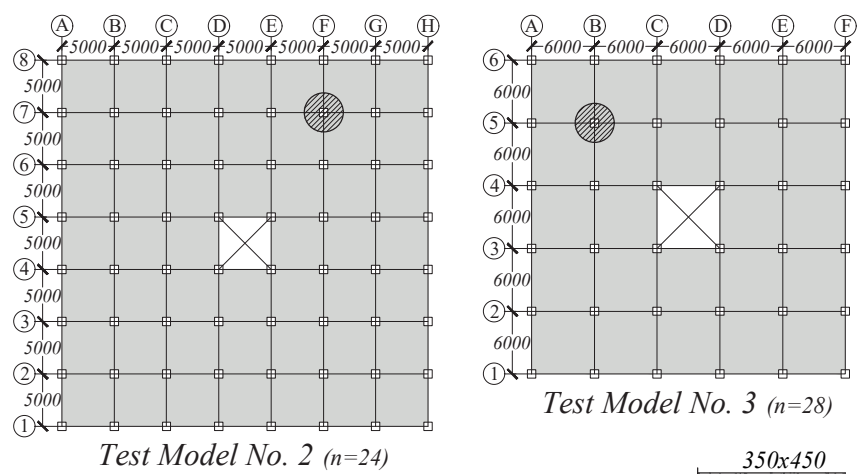

Test Model No. 3 ( $n=28)$

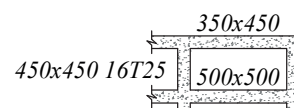

$600 \times 60016720 \quad 550 \times 550$

$650 \times 65016728 \quad 550 \times 650$

$650 \times 65016 T 280600650$

$700 \times 70016725 \quad 650 \times 650$

$750 \times 75016728700 \times 700$

$750 \times 75016728: 700 \times 700$

$750 \times 75016728-700 \times 750$

$750 \times 75016732700 \times 750$

$750 \times 75016732 \quad 700 \times 750$

$800 \times 80020728: 700 \times 800$

$800 \times 80020728700 \times 800$

$800 \times 80020 T 287750 \times 800$

$800 \times 80020 T 28$ 800x800

\begin{tabular}{lll}
$800 \times 80020728$ & $800 \times 800$ \\
$800 \times 80020 T 32$ & $800 \times 800$ \\
\hline
\end{tabular}

$850 \times 85024 T 32800 \times 800$

$850 \times 85024732: 850 \times 800$

$850 \times 85024 T 32 \quad 900 \times 800$

$900 \times 90032 T 28: 950 \times 800$

$900 \times 90032 T 28=950 \times 800$

$900 \times 90032732950 \times 800$

$950 \times 95032 T 32: 950 \times 800$

$950 \times 95032 T 32: 950 \times 800$

$1000 \times 100032 T 32950 \times 800$

$1000 \times 100036732950 \times 800$

$1050 \times 105032 T 32950 \times 800$.

$1050 \times 105040 T 32: 1000 \times 800$

$1050 \times 105044732: 1000 \times 800$

$1100 \times 110044 T 321000 \times 800$

$1150 \times 115044 T 321000 \times 800$ .

$1150 \times 115048732 \quad 1000 \times 800$

$1200 \times 120048 T 32 \quad 1000 \times 800$

$1250 \times 125048732 \quad 1000 \times 800$

$1300 \times 130056 T 32: 3800$

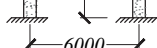

Test Model No. 4

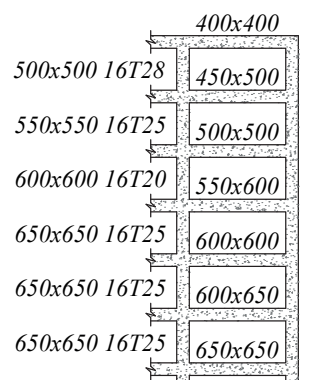

$700 \times 70016728: 650 \times 650$

$700 \times 70020732: 650 \times 700$

$700 \times 70020732 \quad 650 \times 700$

$700 \times 70020732: 650 \times 700$

\begin{tabular}{r:r}
$750 \times 75016732$ & $650 \times 700$ \\
\hline
\end{tabular}

$800 \times 80020728 \quad 650 \times 750$

$800 \times 80020728650 \times 750$

$800 \times 800207280700 \times 750$

$800 \times 80020728750 \times 750$

$800 \times 80020 T 28: 750 \times 750$

$800 \times 80020728.750 \times 750$

$800 \times 80020 T 32750 \times 750$

$850 \times 85024 T 32750 \times 750$

足

$850 x 85024 T 32: 750 x 800$

$850 \times 85024 T 32750 \times 800$

$850 x 85028732750 \times 800$

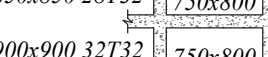

$900 \times 90032 T 32750 \times 800$

$900 \times 90032 T 327750 \times 800$

$950 \times 950327327750 \times 800$

$1000 \times 100032 T 32: 750 \times 800$

$1000 \times 1000327327750 \times 800$

$1000 \times 100036 T 32800 \times 800$

$1050 \times 105036732 \quad 800 \times 800$

$1050 \times 1050407328850 \times 800$

$1100 \times 110040 T 32 \quad 850 \times 800$

$1100 \times 110044 T 32: 900 \times 800$

$900 \times 800$

$1150 \times 115044 T 32900 \times 800$

$1150 \times 115048732900 \times 800$

$1200 \times 120044732000 \times 800$

$1200 \times 120052 T 32.950 \times 800$

$1250 \times 125048 T 32950 \times 800$

$1250 \times 1250567321000 \times 800$

$1250 \times 125056732 \quad 1000 \times 800$ $1300 \times 130056732: 1000 \times 800$

$1300 \times 130060732.1000 \times 800$

$1300 \times 130064 T 32$

$1300 \times 130064 T 32 \quad 1000 \times 800$

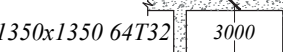

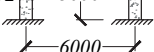

Test Model No. 5 \begin{tabular}{lll} 
& $650 \times 700$ \\
\hline & $00 \times 80020728$ \\
\hline
\end{tabular}

STORY 40

STORY 39

STORY 38

STORY 37

STORY 36

STORY 35

STORY 34

STORY 33

STORY 32

STORY 31

STORY 30

STORY 29

STORY 28

STORY 27

STORY 26

STORY 25

STORY 24

STORY 23

STORY 22

STORY 21

STORY 20

STORY 19

STORY 18

STORY 17

STORY 16

STORY 15

STORY 14

STORY 13

STORY 12

STORY 11

STORY 10

STORY 9

STORY 8

STORY 7

STORY 6

STORY 5

STORY 4

STORY 3

STORY 2

STORY 1

Test Model No.

Test Model No. 3

Fig. 12 Results of conventional and optimized design for sections of structural elements in test models with relevant plans 


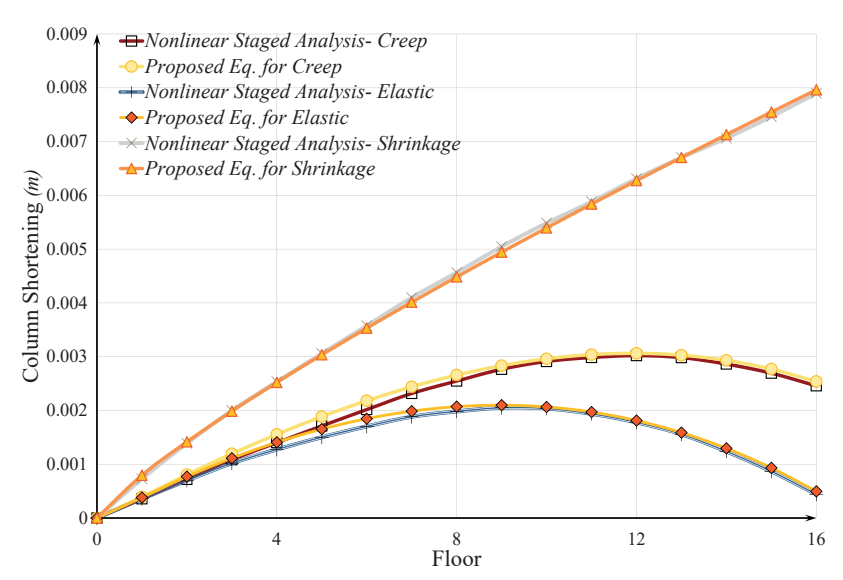

Fig. 13 Comparison of long term shortening in test model number 1

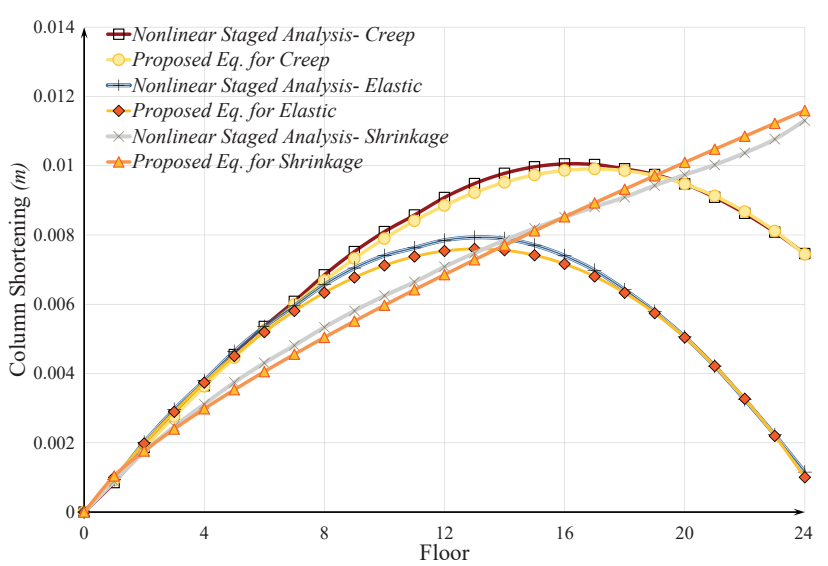

Fig. 14 Comparison of long term shortening in test model number 2

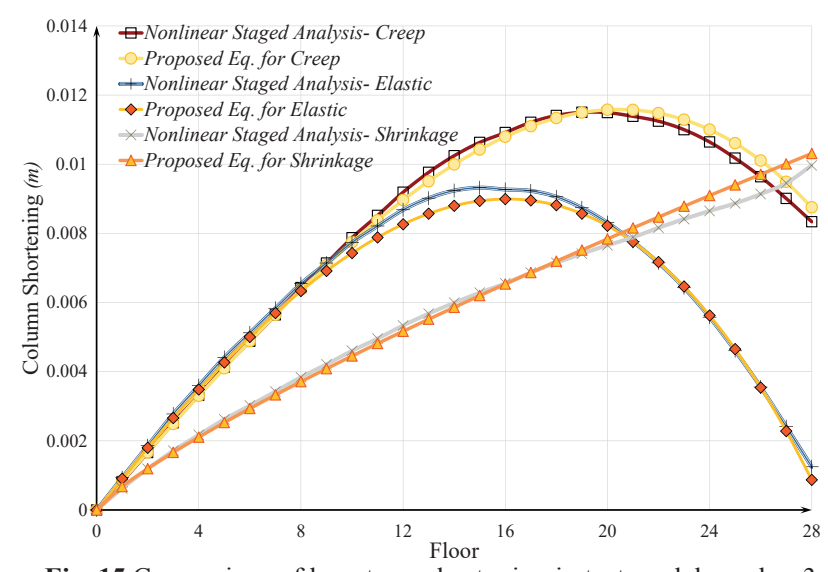

Fig. 15 Comparison of long term shortening in test model number 3

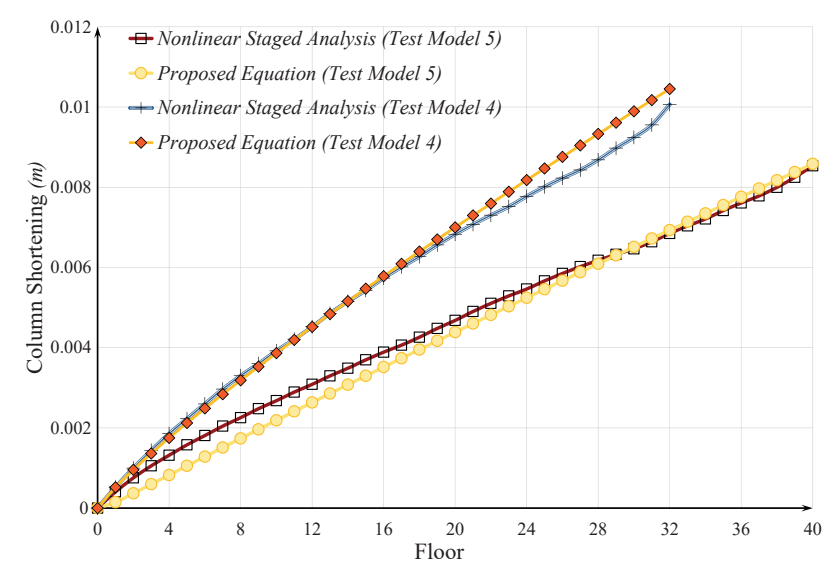

Fig. 16 Comparison of shrinkage shortenings of test models number 4 and 5

\section{Conclusions}

In this article, the long-term behavior of special reinforced concrete moment frame structures in form of time-dependent shortening of column in $1000^{\text {th }}$ day (as the time indicator in which inelastic strains of concrete have occurred) has been evaluated using different non-linear staged analyses and simple empirical equations have been presented and ranges of application of mentioned equations have been proposed using parametric studies and extensive modeling. Simplicity of proposed equations due to their dependent only to geometric characteristics including dimensions of span, height and number of floors and its independence from the conventional parameters of shortening estimation in ACI209R regulations are among the benefits of method used in the present research. Results obtained from the evaluations in this research show that:

- All proposed equations (34 to 36) with coefficients in the Eq. (37) and Tables (6 to 9) have validated for all special concrete moment frames with up to 30 floors with optimal design based on conventional one-step analyses in accordance with ACI318-14 regulations and initial assumptions of the article. The proposed equations can be used instead of time consuming staged analyses for estimation of shortening in different types of columns defined based on equations (25 to 27) and plan in Fig. 7.

- The proposed equation in the present study in terms of shortening caused by shrinkage (Eq. 36) is valid even for structures taller than 30 floors and is able to estimate the effect of column's shrinkage with an acceptable error percentage.

- The shrinkage constants presented in Tables (6 to 9) are almost equal for every type of column. Hence, the proposed equation for shrinkage is independent from situation and tributary area of column and each one of specific proposed series of shrinkage constants can be used to estimate the shrinkage shortenings of all types of columns with a very good approximation.

- The sensitivity of columns in the models of the present research to long-term staged behavior in form of percentage of change in staged axial strain (Including long-term effects) compared to the conventional axial strain (without long-term effects) will significantly increase with increasing number of structure's floors by about 10 floors.

\section{References}

[1] Esmaili, O., Epackachi, S., Mirghaderi, R., Ghalibafian, M., Taheri Behbahani, A. A. "Evaluation of the Construction Sequence Loading Effects on Seismic Performance of High-rise Buildings with Different Structural Systems". In: Ninth Canadian Conference on Earthquake Engineering. Ottawa, Ontario, Canada, Jun. 26-29. 2007. pp. 729-738. http:// www.academia.edu/24982420/Evaluation_of_the_construction_sequence_loading_effects_on_seismic_performance_of_high-rise_buildings_with_different_structural_systems 
[2] Kwak, H.-G., Kim, J.-K. "Time-dependent analysis of RC frame structures considering construction sequences". Building and Environment, 41(10), pp. 1423-1434. 2006. https://doi.org/10.1016/j.buildenv.2005.05.013

[3] Choi, C.-K., Kim, E.-D. "Multistory Frames Under Sequential Gravity Loads". Journal of Structural Engineering, 111(11), pp. 2373-2384. 1985. https://doi.org/10.1061/(ASCE)0733-9445(1985)111:11(2373)

[4] Kim, H., Jeong, S., Shin, S. "Column shortening analysis of tall buildings with lumped construction sequences". The Structural Design of Tall and Special Buildings, 21(10), pp. 764-776. 2012. https://doi.org/10.1002/ tal.650

[5] Njomo, W., Ozay, G. "Sequential analysis coupled with optimized substructure technique modeled on 3D-frame construction process". Engineering Structures, 80, pp. 200-210. 2014. https://doi.org/10.1016/j.engstruct.2014.08.049

[6] Choi, C.-K., Chung, H.-K., Lee, D.-G., Wilson, E. L. "Simplified Building Analysis with Sequential Dead Loads-CFM". Journal of Structural Engineering, 118(4), pp. 944-954. 1992. https://doi.org/10.1061/ (ASCE)0733-9445(1992)118:4(944)

[7] Kim, H., Jeong, S., Shin, S., Park, J. "Simplified column shortening analysis of a multi-storey reinforced concrete frame". The Structural Design of Tall and Special Buildings, 21(6), pp. 405-415. 2012. https://doi. org/10.1002/tal.607

[8] Kim, H. "Effect of horizontal members on column shortening of reinforced concrete building structures". The Structural Design of Tall and Special Buildings, 22(5), pp. 440-453. 2013. https://doi.org/10.1002/ tal.696

[9] Kim, H. "Optimum distribution of additional reinforcement to reduce differential column shortening". The Structural Design of Tall and Special Buildings, 24(10), pp. 724-738. 2015. https://doi.org/10.1002/tal.1208

[10] Sharma, R. K., Maru, S., Nagpal, A. K. "Effect of beam stiffness-column reinforcement on creep and shrinkage behaviour of R.C frames". The Structural Design of Tall and Special Buildings, 18(3), pp. 327-339. 2009. https://doi.org/10.1002/tal.422

[11] Njomo, W. W., Ozay, G. "Minimization of differential column shortening and sequential analysis of RC 3D-frames using ANN". Structural Engineering and Mechanics, 51(6), pp. 989-1003. 2014. https://doi. org/10.12989/sem.2014.51.6.989

[12] Woo Park, S., Woon Choi, S., Seon Park, H. "Moving average correction method for compensation of differential column shortenings in high-rise buildings". The Structural Design of Tall and Special Buildings, 22(9), pp. 718-728. 2013. https://doi.org/10.1002/tal.722

[13] Moragaspitiya, P., Thambiratnam, D., Perera, N., Chan, T. "A numerical method to quantify differential axial shortening in concrete buildings". Engineering Structures, 32(8), pp. 2310-2317. 2010. https://doi. org/10.1016/j.engstruct.2010.04.006

[14] Torres, L., López-Almansa, F., Cahís, X., Bozzo, L. M. "A numerical model for sequential construction, repairing and strengthening of 2-D concrete frames". Engineering Structures, 25(3), pp. 323-336. 2003. https://doi.org/10.1016/S0141-0296(02)00161-X

[15] Lu, J., Wu, J., Luo, X., Zhang, Q. “Time-dependent analysis of steel-reinforced concrete structures". The Structural Design of Tall and Special Buildings, 22(15), pp. 1186-1198. 2013. https://doi.org/10.1002/tal.1079

[16] Afshari, M. J., Kheyroddin, A., Gholhaki, M. "Simplified sequential construction analysis of buildings with the new proposed method". Structural Engineering and Mechanics, 63(1), pp. 77-88. 2017.

[17] Saffarini, H. S., Wilson, E. L. New approaches in the structural analysis of building systems. Research Report No. UCB/SEMM-83/08. Berkeley, USA. 1983.
[18] Esmaili, O. Considering Sequential Construction Methods of Reinforced Concrete High-rise Buildings with Material Time-Dependency Effects. M.Sc. dissertation. University Of Tehran. 2008.

[19] Epackachi, S., Mirghaderi, R., Esmaili, O., Behbahani, A. A. T., Vahdani, S. "Seismic evaluation of a 56-storey residential reinforced concrete high-rise building based on nonlinear dynamic time-history analyses". The Structural Design of Tall and Special Buildings, 21(4), pp. 233-248. 2012. https://doi.org/10.1002/tal.586

[20] ACI Committee 318. Building Code Requirements for Structural Concrete (ACI 318-14). Farmington Hills, Michigan, USA: American Concrete Institute. 2014.

[21] ACl Committee 209. Prediction of Creep, shrinkage, and Temperature Effects in Concrete structure (ACI209R-92). Farmington Hills, MI, USA: American Concrete Institute. 1997.

[22] "ETABS2015 Technical Reference Manual. Integrated Building Design Software". Berkeley, (California, USA): Computer and Structures Inc. 2015.

[23] Fintel, M., Khan, F. R. "Effects of Column Creep and Shrinkage in Tall Structures-Prediction of Inelastic Column Shortening”. ACI Journal Proceedings, 66(12), pp. 957-967. 1969. 10.14359/7444

[24] "Midas Gen 2015 Analysis Reference Manual-General Structural Design System Software". Midas IT. 2015. http://www.midasit.com

[25] ASCE Standard. Minimum Design Loads for Buildings and Other Structures (ASCE 7-10). Reston, VA: American Society of Civil Engineers. 2010. 